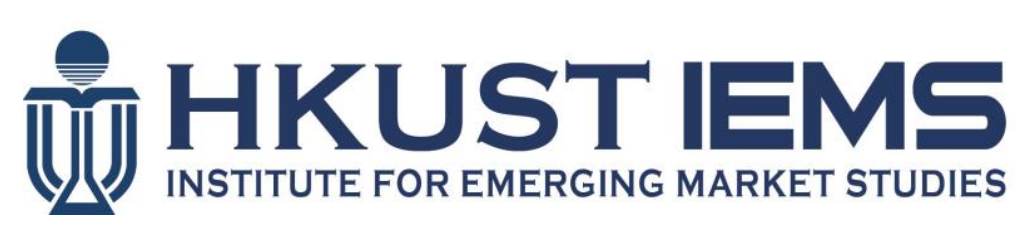

\title{
Import Response to Exchange Rate Fluctuations: A Micro-level Investigation
}

\author{
Yao Amber LI, Jenny XU, Carol Zhao CHEN
}

HKUST IEMS Working Paper No. 2015-27

May 2015

\begin{abstract}
HKUST IEMS working papers are distributed for discussion and comment purposes. The views expressed in these papers are those of the authors and do not necessarily represent the views of HKUST IEMS.
\end{abstract}

More HKUST IEMS working papers are available at: 


\title{
Import Response to Exchange Rate Fluctuations: A Micro-level Investigation
}

Yao Amber LI, Jenny XU, Carol Zhao CHEN

HKUST IEMS Working Paper No. 2015-27

May 2015

\begin{abstract}
This paper presents theory and evidence on firms' import responses to exchange rate fluctuations using disaggregated Chinese imports data. The paper develops a heterogeneous-firm trade model that predicts import responses at both extensive and intensive margins as well as the more profound adjustment under ordinary trade than processing trade. Next, the paper empirically investigates import responses to exchange rate fluctuations at extensive and intensive margins in both the short run and the long run, and confirms the model predictions. We also find variations among import responses under different exchange rate regimes (including fixed exchange rate, expected appreciation, and confirmed appreciation).
\end{abstract}

\section{Authors' contact information}

Yao Amber Li

Department of Economics and Faculty Associate of HKUST IEMS

The Hong Kong University of Science and Technology

$\mathrm{T}:+85223587605$

E: yaoli@ust.hk

W: http://ihome.ust.hk/ yaoli

Jenny Xu

Department of Economics and Faculty Associate of HKUST IEMS

The Hong Kong University of Science and Technology

$\mathrm{T}:+85223587605$

E: jennyxu@ust.hk

Carol Zhao Chen

Department of Economics

The Hong Kong University of Science and Technology

E: zhaochen@ust.hk 


\title{
Import response to exchange rate fluctuations: A micro-level investigation*
}

\author{
Yao Amber $\mathrm{Li}^{\dagger} \quad$ Juanyi Jenny $\mathrm{Xu}^{\ddagger} \quad$ Chen Carol Zhao ${ }^{\S}$ \\ Hong Kong University of Science and Technology
}

This Version: March 2015

First Draft: May 2013

\begin{abstract}
This paper presents theory and evidence on firms' import responses to exchange rate fluctuations using highly disaggregated data of Chinese imports from OECD countries. The paper first develops a heterogeneous-firm trade model and predicts firms' import responses at both the extensive and intensive margins: when domestic currency appreciates, more firms start importing and more products are added into the imported inputs bundle (extensive margin effect), and the import value by each firm also increases (intensive margin effect). The model also predicts that those import responses are more profound for firms in ordinary trade than for those in processing trade. Next, the paper empirically investigates firms' import responses to exchange rate fluctuations at extensive and intensive margins in both the short run and the long run, and all the model predictions are confirmed. The predicted pattern is more robust in the long run than in the short run. We also find variations among import responses under different exchange rate regimes (including a fixed exchange rate regime, an expected appreciation regime, and a confirmed appreciation regime). Finally, we investigate the exchange rate pass-through to import prices and find that incomplete pass-through has declined.
\end{abstract}

Keywords: exchange rate, import, extensive margin, intensive margin, processing trade, exchange rate regimes, pass-through

JEL: F14, F31

${ }^{*}$ We thank David Cook, Keith Head, Shang-Jin Wei, Hiroyuki Kasahara, the participants of the World Congress of the International Economic Association (Jordan, June, 2014), the Asian Meetings of the Econometric Society (Taiwan, June 2014), the 9th Australasian Trade Workshop (Curtin University, March 2014), the "Free-Trade Zone" workshop (Tsinghua University, December 2013), and of seminars held at HKUST for helpful discussions. Yao Amber Li gratefully acknowledges financial support from the Research Grants Council of Hong Kong, China (General Research Funds and Early Career Scheme GRF/ECS Project No. 646112). All errors are our own.

${ }^{\dagger} \mathrm{Li}$ : Corresponding author. Department of Economics and Faculty Associate of the Institute for Emerging Market Studies (IEMS), Hong Kong University of Science and Technology, Hong Kong SAR-PRC. Email: yaoli@ust.hk.

${ }^{\ddagger} \mathrm{Xu}$ : Department of Economics and Faculty Associate of the Institute for Emerging Market Studies (IEMS), Hong Kong University of Science and Technology, Clear Water Bay, Kowloon, Hong Kong SAR-PRC. Email: jennyxu@ust.hk.

$\S$ Zhao: Department of Economics, Hong Kong University of Science and Technology. Email: zhaochen@ust.hk. 


\section{Introduction}

How do importing and exporting firms respond to exchange rate changes? This is a central question in international macroeconomics. This question has become of greater importance recently, given the existence and persistence of substantial global imbalances over the last two decades. Several studies, such as Campa and Goldberg (2005) and Marazzi and Sheets (2007) suggest that exchange rate passthrough to import prices has declined in recent years in industrialized countries. For example, Dong (2012) show that both U.S. exports and imports have become much less responsive to exchange rate movements in recent years and that firms' pricing behavior and global trade patterns may help to explain this decline. Hence, it will be informative to study importing and exporting firms' responses to exchange rate changes using firm-level data because a micro-level analysis could suggest which factors are crucial for understanding firms' responses to exchange rate movement. There are already several studies on this issue using disaggregate-level data, but they mainly focus on the export side (for example, Berman, Martin and Mayer (2012)). In this paper, we intend to study the response of importing firms to exchange rate changes using highly disaggregated Chinese firm-product-level data. Because China is playing an increasingly important role in the global economy, understanding the effect of exchange rate movements on Chinese importing firms is essential for examining the source of trade imbalances and also for predicting the consequences of RMB appreciation on global economy. This paper provides a first step towards enhancing our understanding of this important issue.

The reason to use disaggregated firm-level data to study the import response is twofold. First, existing studies on the Chinese import response to exchange rate fluctuations present ambiguous estimates of the elasticity of Chinese imports with respect to exchange rate changes. The earlier studies find that an appreciation of the RMB would increase Chinese imports (e.g.Dayal-Gulati and Cerra (1999); Dees (2001)), but the more recent ones reach a very different finding (e.g., Lau, Mo and Li (2004); Marquez and Schindler (2007)). For example, Cheung, Chinn and Fujii (2010) find that estimates of the US-China exchange rate elasticity of imports are inconsistent with the standard model. Overall, there is no clear consensus regarding the impacts of real appreciation of the RMB on China's trade balance based on earlier studies. Marquez and Schindler (2007) concludes that the estimated response of imports is negligible and lacks precision. The mixed results in previous studies may be due to the fact that they study Chinese imports using aggregate data at either the industry or the major product level, which leads to contradictions stemming from a lack of firm-level information. That perhaps explains why Garcia-Herrero and Koivu (2009) suggest that the exchange rate policy alone cannot address the trade imbalance. They argue that the real appreciation of the RMB reduces China's trade surplus in the long run, but the effect would be limited in the short run.

Another reason to use firm-level data is that recent research in international trade emphasizes the importance of firms' extensive margins for understanding the overall pattern of imports, the number of goods firms import, and the number of countries from which they import. Previous literature on 
Chinese import response to exchange rate changes often ignores the distinction of different margins of trade. These factors represent the major motivations for our investigation into import response to exchange rate fluctuations using detailed transaction-level Chinese customs data.

To study the response of importing firms to exchange rate changes, we model importing firms' response when facing a domestic currency appreciation using a heterogeneous-firm framework. The model predicts that during appreciation, the threshold productivity for importing decreases, which means that more firms with lower productivity begin importing from abroad. The increasing number of importing firms corresponds to an extensive margin (firm-level) shift. Also, the fixed cost of importing implies that the marginal profit for each imported good increases during appreciation, so the variety of imports increases. This corresponds to an extensive margin shift at product level. With high elasticity of substitution between inputs, the import value per firm (intensive margin) will increase under local currency appreciation as well. However, a currency appreciation may have two-way effects on processing trade profit; the previous pattern could be less robust or even ambiguous when referring to the processing trade. ${ }^{1}$

Our empirical investigation utilizes highly disaggregate (transaction-level) monthly Chinese customs data to evaluate the impact of exchange rate fluctuations on imports. A major advantage of our data is its detailed information on the value and quantity at the HS 8-digit level for each product that each firm imports from each destination country. We can calculate unit value as a proxy for the f.o.b. (free-on-board) import price at the firm-product-country level. Thus, we can estimate both exchange rate elasticity and pass-through at the micro level; this complements the macro literature, which usually studies more aggregate-level trade volume and price index.

This disaggregate dataset enables us to investigate in detail the shift in importing behavior at both firm-level and product-level extensive margins and intensive margin. We first follow the method in Bernard et al. (2009) to decompose aggregate import value into different margins and to examine both cross-sectional and time-series variations in China's imports. We find that two types of extensive margins together contribute to the majority of both the cross-sectional variations and growth over time in China's aggregate imports.

Next, we test both a short-term (monthly basis) and a long-term (quarterly basis) accumulative import response to real exchange rate fluctuations. We first use probit and linear probability regressions to test the probability change in firm entry/exit and product-country adding/dropping in the extensive margin test. We find that firms significantly increase entry and product-country adding probability (and consequently reduce exit and dropping probability) when facing local currency real

\footnotetext{
${ }^{1}$ One distinguishing feature of China's trade is the large proportion of processing trade in total trade volume and the resulting potential interaction between imports and exports (Yu, 2010; Manova and Zhang, 2012). Several papers explore this issue from the exporters' perspective to examine how the processing trade interacts with export price and quantity responses, such as Thorbecke and Smith (2012), Liao, Shi and Zhang (2012), Koopman, Wang and Wei (2012), Xing (2011) and Ahmed (2009). However, not only trade volume but also price behavior could be influenced by the two-way trade (both importing and exporting). For example, Amiti, Itskhoki and Konings (2012) find that firms vary in exchange rate pass-through due to varied import intensity and market shares.
} 
appreciation. In the intensive margin, we test both import value and price changes for a specific firmproduct-country bundle. The results confirm a significant positive coefficient on the real exchange rate for import value and a negative coefficient on import price. Import responses are generally consistent with our model predictions, with the more robust pattern in the long run than in the short run due to the potential time lag in import adjustments.

We then conduct two robustness checks. First, to avoid the concern from seasonal importing firms, we conduct a robustness check using yearly data as a long-run test to complement the previous quarterly test. We find a similar pattern as in the baseline results. Second, to verify the model prediction on processing trade which is a distinct feature of Chinese trade, we test ordinary trade and processing trade samples separately and find that the responses of ordinary traders are indeed more profound than those of processing traders.

In the further discussion part, we test pass-through of nominal exchange rate fluctuation into import prices at the disaggregate HS6-product level because the previous literature finds an interesting decline in import price pass-through mainly based on aggregate data of industrialized countries. Using China's customs data, we are able to explore the pattern of pass-through during RMB appreciation in a developing country. We find that short-run pass-through is highly incomplete: only approximately 15 percent of exchange rate fluctuations would pass-through into the change in import prices (denominated in RMB) within three months. In the long run (within a year) the pass-through elasticity grows into 50 percent gradually. More importantly, there is a declining pass-through to import prices in both the long run and the short run, but this decline is more profound in the long run.

Another special feature of Chinese trade is the transition between different exchange rate regimes during our sample period which offers a unique laboratory to test trade response to policy change. On July 21, 2005, China announced a move from a fixed exchange rate regime to a managed floating exchange rate regime. Afterwards, a series of appreciations of the RMB against the US dollar took place. However, before the official announcement of this reform in 2005, China had already been under great pressure for RMB appreciation, and thus the market had already anticipated a subsequent appreciation of RMB since 2003 according to evidence from forward rates in foreign exchange market. Thus, we segment the whole sample period into three phases (before 2003, 2003-July 2005, and after July 2005). We find that firms respond differently to exchange rate shocks under different regimes including a fixed exchange rate regime, an expected appreciation and a confirmed appreciation regime.

Our study is related to several branches of the literature. The first branch is the international macroeconomics literature using aggregate-level import (export) data and focusing on the exchange rate elasticity of import (export) price, e.g., Campa and Goldberg (2002);Campa and Goldberg (2005); Marazzi and Sheets (2007); and Dong (2012). ${ }^{2}$ The second branch of the literature uses a disaggregate-

\footnotetext{
${ }^{2}$ Campa and Goldberg (2005), for example, find a partial pass-through of exchange rates into import prices in the short run and a dominant effect in the long run, especially for countries with high exchange rate volatility.
} 
level data set but focuses on the export side (e.g., Berman, Martin and Mayer, 2009). ${ }^{3}$ Within this branch, there are a few papers exploring the response of Chinese exporters to exchange rate changes, such as Yu (2009), Li et al. (2012), Tang and Zhang (2012) and Thorbecke and Smith (2010). Our paper, instead, focuses on the response of importers using Chinese customs firm-level data. The third branch of the literature uses disaggregate data to study importers' behavior under crisis or devaluation (e.g., Gopinath and Neiman, 2014; Lu, Mariscal and Mejia, 2012). ${ }^{4}$ Our study focuses on the response of Chinese importers under exchange rate reforms.

Our paper is also related to studies focusing on different margins of trade. For example, Chaney (2008), Arkolakis (2010), Eaton, Kortum and Kramarz (2011), and Bernard et al. (2009) find evidence of extensive margin accounts for a larger share of variation in imports and exports across countries. Also, Hummels and Klenow (2005) argues that the extensive margin at product bundle level plays an important role in trade value.

The rest of the paper is organized as follows. Section 2 builds a simple model to capture import response to exchange rate fluctuation at both the extensive and intensive margins as well as to capture the difference between processing and ordinary traders. Section 3 describes the data and Section 4 presents stylized facts of Chinese import in terms of both the extensive and intensive margins. Section 5 provides detailed tests to verify the predictions from the model. Section 6 presents robustness checks. Section 7 further discusses different import responses under different exchange rate regimes and the exchange rate pass-through into import prices at product level. The last section concludes.

\section{A Simple Model}

We build a simple monopolistic competition model to examine firms' import responses to exchange rate fluctuations by extending Gopinath and Neiman (2014). We first consider an ordinary trade firm, while at the end of this section, we compare a processing trade firm with an ordinary trade firm.

\subsection{The Firm's Production Problem}

It is assumed that firm $i$ draws its productivity from a uniform distribution with support $\left(0, A_{\max }\right)$ and follows the production function of

$$
Y_{i}=A_{i}\left(K_{i}^{\alpha} L_{i}^{1-\alpha}\right)^{1-\mu} X_{i}^{\mu}
$$

\footnotetext{
${ }^{3}$ Berman, Martin and Mayer (2009) examines heterogeneous exporters' adjustments in prices and export volume in response to exchange rate movements using French firm data.

${ }^{4}$ Gopinath and Neiman (2014) explores the mechanism of trade adjustment during the Argentine crisis from 1996-2008. They find that within-firm input churning or the sub-extensive margin, rather than the firm- level extensive margin, played a significant role in the import collapse during the crisis in Argentina. Also, Lu, Mariscal and Mejia (2012) use Columbian trade data and find that firms select import varieties and reorganize their imported inputs and production over time under devaluation.
} 
Given its productivity $A_{i}$, firm $i$ chooses capital input $K_{i}$, labor input $L_{i}$ and intermediate input bundle $X_{i}$, which is a CES aggregate of domestic intermediates $Z_{i}$ and imported intermediates $M_{i}$, with a elasticity of substitution $\rho$. That is, the intermediate input bundle is defined as

$$
X_{i}=\left[Z_{i}^{\rho}+M_{i}^{\rho}\right]^{\frac{1}{\rho}}, \text { where } \rho<1
$$

The price of final intermediate input bundle $P_{X i}$ is given by equation (3)

$$
P_{X i}=\left(P_{Z i}^{\frac{\rho}{\rho-1}}+P_{M i}^{\frac{\rho}{\rho-1}}\right)^{\frac{\rho-1}{\rho}}
$$

For simplicity, we normalize the domestic intermediate input price to one and assume that $P_{M i} \leq 1 .^{5}$ Then we have

$$
P_{X i}=\left(1+P_{M i}^{\frac{\rho}{\rho-1}}\right)^{\frac{\rho-1}{\rho}} \leq 1
$$

Therefore, if a firm only uses domestic intermediate inputs, the input price index is one; if it uses imported intermediate inputs, the price index is less than one.

The imported intermediate input bundle is assumed to be an aggregation of different imported varieties $j, j \in[1, N]$. If the price of variety $j$ is $p_{m j}$, the price index of the imported intermediate bundle, $P_{M i}$, follows

$$
P_{M i}=\left[\int_{j=1}^{N} p_{m j}^{\frac{\theta}{\theta-1}}\right]^{\frac{\theta-1}{\theta}}, \theta<1
$$

where $\theta$ is the elasticity of substitution across imported foreign varieties.

From equation (5), price index $P_{M i}$ is a function of the number of varieties imported, N, and the price of imported variety $j, p_{m j}$. Generally speaking, the price index of imported bundle $P_{M i}$ is a decreasing function of the number of varieties imported. To see this, we consider a simple case where the prices of all imported input varieties are identical. Thus, we can use price $p_{m}$ to denote the price for all varieties. The price index for the imported input bundle is then simply $P_{M i}=N^{\frac{\theta-1}{\theta}} p_{m}$. Because $\theta<1, P_{M i}$ decreases in N.

Imported input price $P_{M i}$ is assumed to be a function of the exchange rate of the domestic currency, $P_{M i}(e)$, where the exchange rate $e$ is defined as the price of domestic currency in terms of foreign currency. ${ }^{6}$ Hence, an appreciation of the domestic currency implies an increase in the exchange rate $e$. Thus, we have $\frac{\partial P_{M i}}{\partial e}<0$, and an appreciation of the domestic currency will lead to a decrease in import prices. In the empirical part, we will investigate the import price changes in response to exchange rate fluctuations because this constitutes an important channel through which exchange rate

\footnotetext{
${ }^{5}$ This assumption ensures that $P_{X i}$, the price of the intermediate input bundle, is less than one. Intuitively, if $P_{X i}$ is larger than one, i.e., the normalized domestic intermediates' price, producers have no incentive to use imported intermediates.

${ }^{6}$ In this simple model, we assume that not all export firms in the exporting country choose local currency pricing when setting export prices. This implies that exchange rate fluctuations will always be passed through to the import price in destination countries. In other words, the price of imported intermediates will change when the exchange rate changes.
} 
changes affect imports.

Consequently, a reduction in $P_{M i}$ generates a decline in $P_{X i}$. Therefore, an appreciation of domestic currency reduces the price index of intermediate inputs as long as firm $i$ imports from abroad.

$$
\frac{\partial P_{X i}}{\partial e}<0
$$

Overall, the unit cost of goods produced by firm $i$ is

$$
C_{i}=\frac{1}{\mu^{\mu}(1-\mu)^{1-\mu}} \frac{P_{V}^{1-\mu} P_{X i}^{\mu}}{A_{i}}, \text { where } P_{V}=\alpha^{-\alpha}(1-\alpha)^{\alpha-1} r^{\alpha} w^{1-\alpha}
$$

Because our model is a partial equilibrium model, capital price $r$ and labor price $w$ are both exogenously determined. We assume that they are constant, implying that the price of non-intermediate inputs $P_{V}$ is identical for all firms. Under this framework, heterogeneity of cost only comes from the firm's own productivity $A_{i}$ and intermediate input bundle $P_{X i}$. Define $\phi=\frac{1}{\mu^{\mu}(1-\mu)^{1-\mu}} P_{V}^{1-\mu}$; the cost function for firm $i$ is then given by

$$
C_{i}=\phi \frac{P_{X i}^{\mu}}{A_{i}}
$$

Thus, within the same sector or industry, we only have to focus on heterogeneity in $A_{i}$ and $P_{X i}$.

\subsection{The Firm's Import Decision}

\subsubsection{Demand Side}

We assume a downward sloping demand function for goods produced by firm $i$,

$$
Y_{i}=o P_{i}^{-\eta} \text {, where } \eta>1 \text { and } o \text { is a constant }
$$

where $P_{i}$ is the price of good i. Profit maximization implies that firm i sets a constant mark-up over its unit $\operatorname{cost} C_{i}$

$$
P_{i}=\frac{\eta}{\eta-1} C_{i}
$$

\subsubsection{The Firm's Problem}

The profit for firm $i$ is denoted by $\pi_{i}$, which equals revenue minus the fixed cost of production. If a firm imports, it incurs an additional fixed cost of importing, $F_{i m p}$, and a variable import cost $f_{i m p}(N)$, which depends on $N$, the number of varieties imported. It is assumed that $f_{i m p}(N)$ increases with $\mathrm{N}$ and is a convex function of $\mathrm{N}$.

$$
\pi_{i}=Y_{i} P_{i}-Y_{i} C_{i}-F_{i m p}-f_{i m p}(N)
$$




$$
\begin{gathered}
\pi_{i}=o \frac{1}{\eta}\left(\frac{\eta}{\eta-1}\right)^{1-\eta}\left(\frac{1}{\mu^{\mu}(1-\mu)^{1-\mu}} \frac{P_{V}^{1-\mu} P_{X i}^{\mu}}{A_{i}}\right)^{1-\eta}-F_{i m p}-f_{i m p}(N) \\
\pi_{i}=\lambda\left(\frac{P_{X i}^{\mu}}{A_{i}}\right)^{1-\eta}-F_{i m p}-f_{i m p}(N), \text { where } \lambda=o\left(\frac{\eta}{\eta-1}\right)^{1-\eta} \phi^{1-\eta} \frac{1}{\eta} \text { is a constant }
\end{gathered}
$$

Taking the logarithm of the first term in the profit function above, we obtain the following equation 10 (using lower case letters to denote the logarithm).

$$
\begin{gathered}
R=\lambda\left(\frac{P_{X i}^{\mu}}{A_{i}}\right)^{1-\eta} \\
r=\bar{\lambda}+(\eta-1)\left(a_{i}-\mu p_{x i}\right) \text { where } \bar{\lambda}=\log (\lambda)
\end{gathered}
$$

\subsubsection{The Extensive Margin Decision at Firm Level}

In our model, a firm faces a trade-off between reducing production cost by importing more from abroad and the potential incurred cost of importing. The productivity threshold of importing can be solved from the zero profit condition. Facing a variable import cost, the more varieties that a firm imports, the higher cost it must pay. The cut-off value of productivity for imports, $a_{i}^{*}$, is given by the following equation.

$$
a_{i}^{*}=\frac{\log \left[F_{i m p}+f_{i m p}(N)\right]-\bar{\lambda}}{\eta-1}+\mu p_{x i}
$$

Given variety $N$, because $p_{x i}$ decreases when domestic currency appreciates, the cut-off productivity consequently decreases.

$$
e \uparrow, a_{i}^{*} \downarrow, i . e ., \frac{\partial a_{i}^{*}}{\partial e}<0
$$

This implies that the mass of importing firms shifts from $\left(a_{i}^{*}, a_{\max }\right)$ to $\left(a_{i}^{\prime *}, a_{\max }\right)$, where $a_{i}^{\prime *}<a_{i}^{*}$, and more firms start to import after a currency appreciation.

Proposition 1. When domestic currency appreciates, more firms start to import from abroad, which suggests an increase in the extensive margin of imports at firm level.

\subsubsection{The Extensive Margin Decision at Product Level}

How do imported varieties respond to appreciation? Given productivity $a_{i}$, firm $i$ chooses the optimal $N$ to maximize its profit function

$$
N^{*}=\underset{N}{\arg \max }\left[\lambda\left(\frac{P_{X i}^{\mu}(N)}{A_{i}}\right)^{1-\eta}-F_{i m p}-f_{i m p}(N)\right]
$$


Under our assumption, the firm incurs a variable cost $f_{\text {imp }}(N)$ to import from abroad. To discover the effect, we first define the marginal benefit of increasing the import variety as follows:

$$
M B(N)=\lambda(1-\eta) \mu A_{i}^{\eta-1} P_{X i}^{-\mu \eta+\mu-1} \frac{\partial P_{X}}{\partial P_{M i}} \frac{\partial P_{M i}}{\partial N}
$$

As shown in Section 2.1, the price index of intermediate imported input $P_{M i}$ decreases with the number of imported varieties $N$, i.e., $\frac{\partial P_{M i}(N)}{\partial N}<0$. Thus the price index of intermediate input bundle $P_{X i}$ also decreases in $N$, i.e., $\frac{\partial P_{X i}(N)}{\partial N}<0$. Because $\eta>1$, we have $M B(N)>0$.

From equation (12), we can also define the marginal cost of an extra imported variety, given by

$$
M C(N)=\frac{\partial f_{i m p}(N)}{\partial N}>0
$$

Because $f_{\text {imp }}(N)$ increases with $\mathrm{N}$ and is a convex function of $\mathrm{N}$, the marginal cost $M C(N)$ of importing intermediate input is positive and increasing in $N$.

When domestic currency appreciates, $\mathrm{MB}(\mathrm{N})$ will also be affected because $P_{X i}$. The price level of the intermediate input bundle decreases due to the appreciation. Meanwhile, $\frac{\partial P_{M i}(N)}{\partial N}$ is also a function of $e$. Intuitively, as long as the elasticity between imported and domestic intermediates is low, the marginal benefit of importing an extra variety increases when $e$ increases. ${ }^{7}$ This implies that the MB curve shifts upward when currency appreciates.

From equation (12), the optimal number for imported variety $N^{*}$ becomes the intersection of the marginal cost (MC) and marginal benefit (MB) equations. Note that $M C(N)$ is independent of the exchange rate. Therefore, as illustrated in Appendix A, as long as the slope of the MC curve is larger than the slope of the MB curve, when the marginal benefit curve shifts upwards because domestic current appreciates, the intersection point $N^{*}$ will rise, which implies an increase in the number of imported varieties for an importing firm.

Proposition 2. When domestic currency appreciates, a firm tends to import more varieties from abroad, which suggests an increase in the extensive margin of imports at product level.

Proof: See Appendix A.

\subsubsection{The Firm's Intensive Margin Decision}

Given its choice to import or not and the number of importing varieties, firm $i$ minimizes its cost by choosing the optimal composition of domestic input $Z_{i}$ and imported input $M_{i}$ to produce the intermediate input. In this section, we focus on the response of the intensive margin to exchange rate fluctuations, so we will treat $M_{i}$ as a single variety of imported input with price $P_{M i}$.

\footnotetext{
${ }^{7}$ Consider the previous simple case where $p_{m j}=p_{m}, P_{M i}=N^{\frac{\theta-1}{\theta}} p_{m}(e)$. We show that when $\rho$ is small enough, the $\mathrm{MB}(\mathrm{N})$ function is an increasing function of $e$. For a detailed proof, please see Appendix A.
} 


$$
\begin{aligned}
& \min _{Z, M}\left[P_{z i} Z_{i}+P_{M i} M_{i}\right] \\
& \text { s.t. }\left[Z_{i}^{\rho}+M_{i}^{\rho}\right]^{\frac{1}{\rho}}=1
\end{aligned}
$$

Solving the cost minimizing problem yields the optimal input for both imported and domestic intermediate inputs $M_{i}^{*}$ and $Z_{i}^{*}$ to produce one unit of the intermediate input bundle.

$$
\begin{gathered}
M_{i}^{*}=\left(1+P_{M i}^{\frac{-\rho}{\rho-1}}\right)^{\frac{-1}{\rho}} \\
Z_{i}^{*}=P_{M i}^{\frac{-1}{\rho-1}} M_{i}^{*}
\end{gathered}
$$

Because $\frac{\partial P_{M i}}{\partial e}<0, \frac{\partial M_{i}^{*}}{\partial P_{M i}}<0$ and $\rho<1$, we have $\frac{\partial M_{i}^{*}}{\partial e}>0$, implying that imports from abroad $M_{i}$ should rise as the exchange rate increases.

$$
e \uparrow, P_{M i}(e) \downarrow, M_{i}^{*}(e) \uparrow
$$

If we define the expenditure on the imported intermediate input as $C_{m}$, we can see that it is a function of exchange rate $e$.

$$
C_{m}(e)=\left(1+P_{M i}^{\frac{-\rho}{\rho-1}}\right)^{-\frac{1}{\rho}} P_{M i}(e)
$$

Because $\frac{\partial P_{M i}}{\partial e}<0$, imported value $C_{m}$ is an increasing function of exchange rate $e$ given that substitution elasticity between domestically produced and imported intermediates is high and that the price of the imported intermediates is not too low. In the numerical analysis, we show that this condition holds. ${ }^{8}$ This implies that if domestic currency appreciates, expenditure on imports increases. That is

$$
e \uparrow, P_{M i}(e) \downarrow, C_{m}(e) \uparrow \text { if } \rho \text { satisfies certain condition }
$$

Proposition 3. When the domestic currency appreciates, the intensive margin of imports, i.e., the total expenditure on imported intermediate inputs, increases.

\subsection{Global Value Chain}

Up to now, our model has focused on ordinary trade firms. In this subsection, we explore a scenario in which firms engage in the global value chain and perform processing trade. In this scenario, a processing-trade firm may engage in pure assembly using imported intermediates provided by foreign partners, or it may import intermediate inputs and produce final products to export. In both cases,

\footnotetext{
${ }^{8}$ The following condition must be satisfied: $\left(1+P_{M}^{\frac{\rho}{\rho-1}}\right)(\rho-1)>-1$. This condition is satisfied if $\rho>\rho^{*}=\arg \{\rho=$ $\left.\frac{P_{M}^{\frac{\rho}{\rho-1}}}{1+P_{M}^{\frac{\rho}{\rho-1}}}\right\}$

can verify that as long as $P_{M}$ is reasonably large within the range of $[0,1]$, and $\rho$ is sufficiently large, the above condition can be satisfied. Gopinath and Neiman (2014) set $\rho$ to be approximately 0.75 in calibration. Given this value of $\rho$, the above condition is satisfied.
} 
facing exchange rate changes, the marginal benefit for the importing form of firms will be different from that for ordinary trade firms. In the first case, or the so-called pure assembly-trade case, there is little change in input cost because the intermediate input is directly provided by foreign firms. In this sense, there is no incentive for Chinese assembly firms to change import values when facing exchange rate fluctuations. However, if a firm engages in the processing trade and imports intermediate inputs, then the import response to exchange rate fluctuations would be different.

We use a simple model to illustrate this point. We assume that firm $i$ uses imported and domestic intermediate goods to produce export goods. The setting regarding the price and quantity of domestic and imported intermediates is the same as in the model above. So the cost of the export good is also $C_{i}=\frac{1}{\mu^{\mu}(1-\mu)^{1-\mu}} \frac{P_{V}^{1-\mu} P_{X i}^{\mu}}{A_{i}}$, where $P_{V}$ and $P_{X i}$ are defined similarly as in the ordinary trade model.

We also assume that processing trade firm $i$ has a foreign partner. The foreign partner services consumers abroad and entails an additional outlay cost, $T$, for marketing purposes and to manage a distribution network. $T$ may also include up-front sunk costs paid by firm $i$ 's foreign partner. The foreign partner and the processing-trade firm $i$ engage in a Nash-bargaining game with bargaining weights corresponding to their contribution to the collaborated production. To be specific, we assume that these weights reflect the share of total costs borne by each side. Under this setting, the processing trade firm would only reap a proportion of the total profit $\pi_{i}$, and the proportion will depend on its input share.

To derive the profit equation, we assume that in the international market, there is a downward demand for goods produced by firm $i$.

$$
Y_{i}^{*}=o\left(P_{i}^{*}\right)^{-\eta}
$$

where $P_{i}^{*}$ is the foreign currency price of good $i$ and $o$ is a constant. Because we have flexible prices, the price faced by foreigners is the same regardless of whether the firm uses producer currency pricing or local currency pricing. ${ }^{9}$ Suppose firm $i$ follows the producer's currency when setting the export price, given that $P_{i}=\frac{\eta}{\eta-1} C_{i}$. Then, it sets the exporting price as

$$
P_{i}^{*}=e P_{i}=e \frac{\eta}{\eta-1} C_{i}
$$

Hence, the profit that processing-trade firm $i$ obtains from production is given by

$$
\begin{gathered}
\pi_{i}^{P T}=Y_{i}^{*} P_{i}^{*}-Y_{i}^{*} C_{i}-F_{i m p}-f_{i m p}(N)-T \\
\pi_{i}^{P T}=e^{-\eta} o\left(\frac{\eta}{\eta-1}\right)^{-\eta} \frac{1}{\eta-1} C_{i}^{1-\eta}-F_{i m p}-f_{i m p}(N)-T
\end{gathered}
$$

As mentioned above, the profit that processing-trade firm $i$ receives is proportional to its input share.

\footnotetext{
${ }^{9}$ If firm $i$ adopts local currency pricing, the optimal price set by firm $i$ is given by $P_{i}^{*}=e \frac{\eta}{\eta-1} C_{i}$. So the demand follows $Y_{i}^{*}=o\left(e \frac{\eta}{\eta-1} C_{i}\right)^{-\eta}$, and the profit in terms of the domestic currency is $\pi=\frac{P_{i}^{*} Y_{i}^{*}}{e}-Y_{i}^{*} C_{i}-F_{i m p}-f_{i m p}(N)-T$. Hence, the profit denoted in domestic currency is the same as in equation (20).
} 
Using the notation from the ordinary trade model, define $\lambda=o\left(\frac{\eta}{\eta-1}\right)^{-\eta} \frac{1}{\eta-1} \phi^{1-\eta}$; the profit that the processing-trade firm receives $\pi_{i}$ becomes

$$
\pi_{i}=\left[\lambda e^{-\eta}\left(\frac{P_{X i}^{u}}{A_{i}}\right)^{1-\eta}-F_{i m p}-f_{i m p}(N)-T\right]\left(\frac{C_{i}+f_{i m p}(N)+F_{i m p}}{C_{i}+f_{i m p}(N)+F_{i m p}+T}\right)
$$

We define $\pi^{P T}=\lambda e^{-\eta}\left(\frac{P_{X i}^{u}}{A_{i}}\right)^{1-\eta}-F_{i m p}-f_{i m p}(N)$ and $B=\frac{C_{i}+f_{i m p}(N)+F_{i m p}}{C_{i}+f_{i m p}(N)+F_{i m p}+T}$, where $B$ denotes the share of inputs contributed by processing firm $i$. Then, profit for processing-trade firm $i$ follows $\pi_{i}=\pi^{P T} * B$. Let the profit of a parallel importing firm $j$ that engages in ordinary trade be denoted as $\pi^{O D}$, and $\pi^{O D}=\pi^{P T}+T$. Then we have

$$
\frac{\partial \pi_{i}}{\partial e}=\frac{\partial \pi^{P T}}{\partial e} B+\frac{\partial B}{\partial e} \pi^{P T}
$$

We can show that

$$
\frac{\partial \pi^{P T}}{\partial e}=-\eta e^{-\eta-1} \lambda\left(\frac{P_{X i}^{u}}{A_{i}}\right)^{1-\eta}+e^{-\eta} \frac{\partial \pi^{O D}}{\partial e}<e^{-\eta} \frac{\partial \pi^{O D}}{\partial e}
$$

and

$$
\frac{\partial B}{\partial e}<0, \text { with } \frac{\partial C_{i}}{\partial e}<0
$$

First, due to the presence of $e^{-\eta}$ in the revenue function, compared to the parallel ordinary trade firm, the profit increase of the processing firm is smaller, as shown by expression (22). Intuitively, this is because when the domestic currency appreciates, export good $i$ becomes more expensive and foreign demand decreases, which in turn reduces the profit gain of the firm due to cost reductions after exchange rate appreciation. Second, as the exchange rate increases, for processing trade firm $i$, costs reduce and profit rises, while the bargaining power of firm $i$ decreases as the input share $\mathrm{B}$ decreases. So the profit increases after the currency appreciation shrinks for the processing firm.

Hence, due to the above two effects, the response of importers to exchange rate fluctuations for processing-trade firms should be weaker than for ordinary trade firms. In particular, if the two adverse effects are large enough, the import responses of the processing trade firm to exchange rate fluctuation may become ambiguous. In summary, we have the following proposition.

Proposition 4. When domestic currency fluctuates, processing-trade firms tend to have less or even ambiguous import response compared to ordinary trade firms.

\section{Data}

Our empirical investigation is built upon highly disaggregated trade data for Chinese importing firms and their imported products as well as on bilateral exchange rates between China and its trading partners. 


\subsection{Transaction-level trade data}

The import data come from Chinese transaction-level trade data, maintained by China's General Administration of Customs. This database records monthly data for all Chinese export and import transactions between 2000 and 2006, including import and export values (denominated in US dollars), quantities, quantity units, HS 8-digit product classification, firm identity information, trade destinations/origins, type of enterprises (e.g., state owned, domestic private firms, foreign invested, and joint ventures), and customs regimes (e.g., "Processing and Assembling" and "Processing with Imported Materials"). Specifically, import data from 29 OECD countries are included in our empirical investigation, which accounts for a majority of China's total import value (approximately 54-60 percent) from 2000 to $2006 .^{10}$

\subsection{Exchange rate data}

\section{Nominal exchange rates}

Nominal exchange rates are obtained from the Bloomberg Daily Exchange Rate Database. As we only need monthly data, the average monthly exchange rates are calculated as the mean of the spot daily exchange rates for that month. The Bloomberg Daily Exchange Rate Database covers all spot exchange rates between China and her 29 OECD trading partners using 16 currencies: USD, AUD, EUR, CAD, DKK, HUF, NZD, GBP, JPY, SEK, KRW, NOK, CHF, MXN, PLN, and CZK. ${ }^{11}$

\section{Real exchange rates}

We use real exchange rates instead of nominal exchange rates in the empirical tests of import response to exchange rate fluctuations. To construct real exchange rates, the monthly consumer price index (CPI) is obtained from the IMF website. $C P I$ and $C P I_{c}$ represent the consumer price index of China and of the corresponding import partner country $c$, respectively. We use $e_{c}$ and $E_{c}$ to denote the real exchange rate and the nominal exchange rate between the home country, China, and foreign country $c$, respectively. $E_{c}$ is defined as the price of the domestic currency in terms of the foreign currency of country $c$, for example, $E_{U S}$ was 0.125 in 2006, i.e., one Chinese yuan was worth 0.125 USD in 2006 according to official nominal exchange rates. Under this definition, an increase in $E_{c}$ represents an appreciation of the domestic currency against a foreign currency. Then, the bilateral real exchange rate is given by

$$
e_{c}=\frac{E_{c} \times C P I}{C P I_{c}}
$$

To be consistent with the customs trade data, real exchange rates in our analysis cover the period

\footnotetext{
${ }^{10}$ The sample countries include Australia, Austria, Belgium, Canada, the Czech Republic, Denmark, Finland, France, Germany, Greece, Hungary, Iceland, Ireland, Italy, Japan, Luxembourg, Mexico, the Netherlands, New Zealand, Norway, Poland, Portugal, the Republic of Korea, Spain, Sweden, Switzerland, Turkey, the United Kingdom, and the United States. We chose these countries because they are among China's top trading partners and also because of the availability of the bilateral exchange rates.

${ }^{11}$ Note that some countries share a common currency, such as EU countries.
} 
from January 2000 to December 2006. We use a log difference to measure the change in the bilateral real exchange rate between China and country $c$ during a certain time interval at either monthly or quarterly frequency:

$$
\Delta e_{c t}=\log \left(\frac{E_{c, t}}{E_{c, t-1}}\right)+\log \left(\frac{C P I_{t}}{C P I_{t-1}}\right)-\log \left(\frac{C P I_{c, t}}{C P I_{c, t-1}}\right) .
$$

\subsection{China's exchange rate reform and currency appreciation}

Before July 2005, China followed a fixed exchange rate regime with the RMB pegged to the US dollar. In July 2005, China announced the adoption of a managed floating exchange rate regime to replace the fixed regime. Under the managed floating regime, based on market supply and demand, exchange rates of RMB against USD are set with reference to a basket of foreign currencies. Figure 1 depicts fluctuations of both nominal and real exchange rates for RMB against USD from 2000 to 2006. As illustrated in Figure 1, nominal exchange rates between RMB and USD did not change before 2005, and fluctuations of nominal exchange rates only occur after the regime shift in 2005. Nevertheless, the fluctuations of real exchange rates of the RMB against the USD are observed over the entire sample period. The increasing trends imply an appreciation of the RMB against the USD in both nominal and real exchange rates.

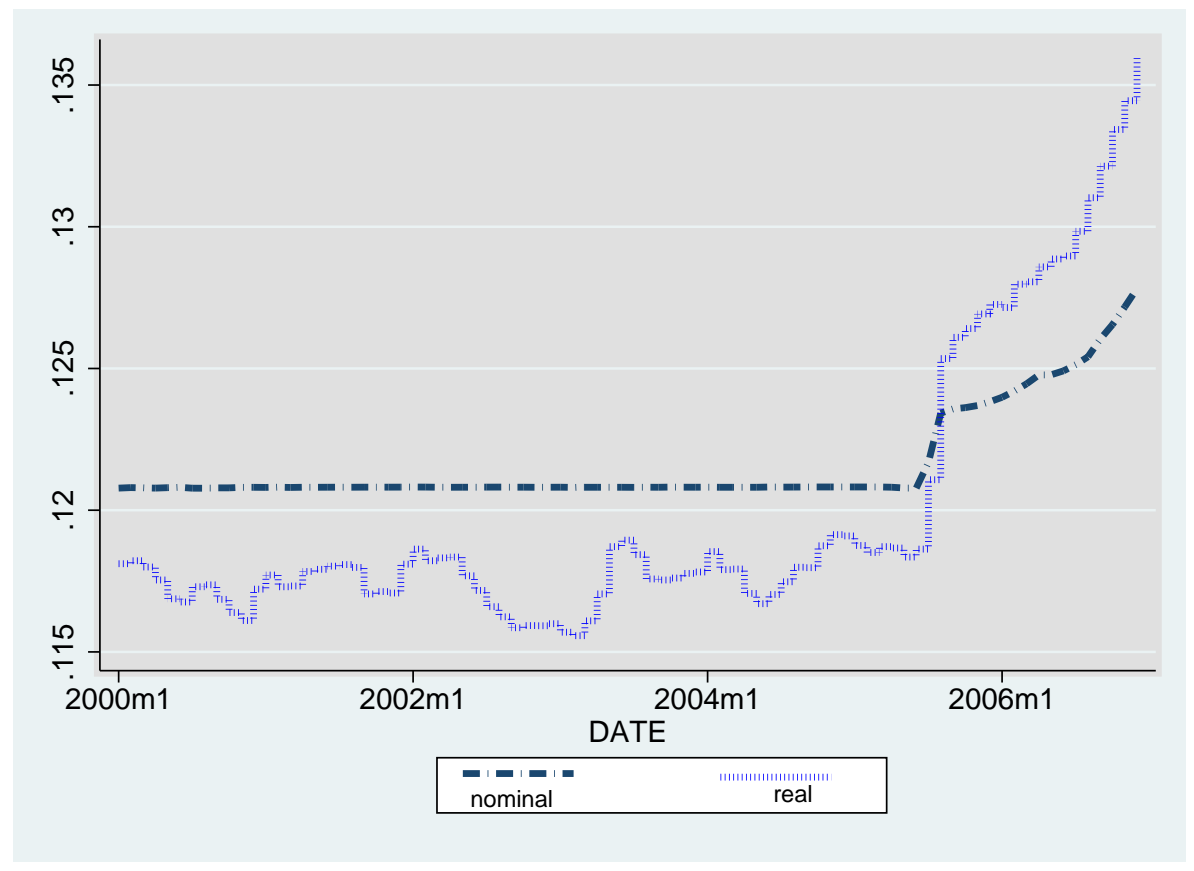

Figure 1: Nominal and Real Exchange Rate Fluctuation 


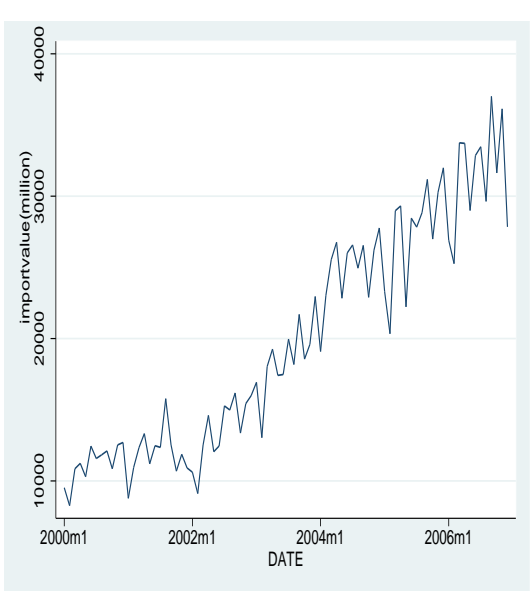

(a) Aggregate Import Value

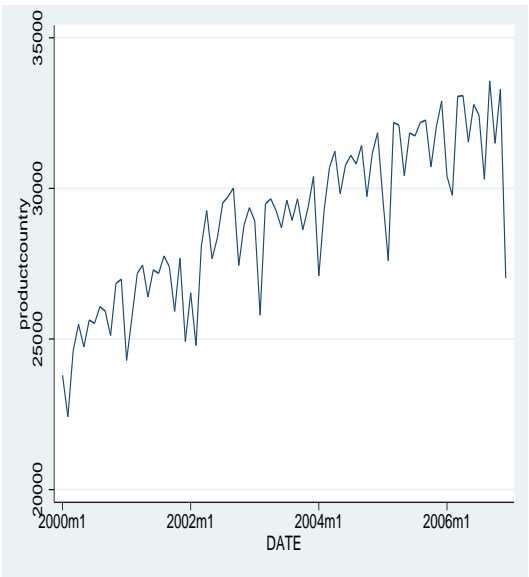

(b) Number of Product-Country

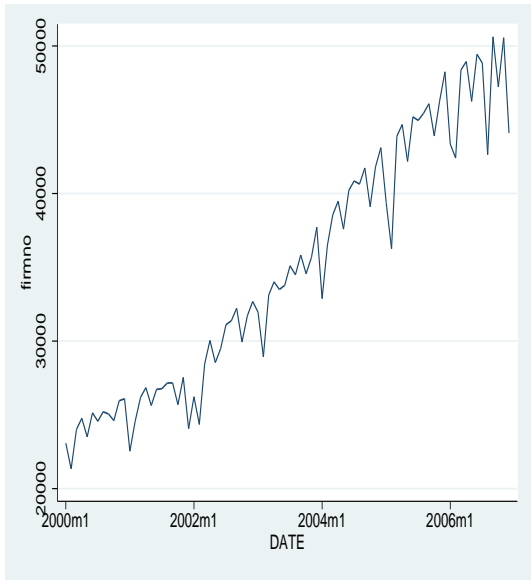

(c) Number of Importing Firms

Figure 2: Time trend of import value and decomposition

\section{Stylized facts for China's imports}

In this section, we present some stylized facts for China's imports, including aggregate import value and changes in different import margins.

\subsection{Aggregate import value and its decomposition}

Using transaction-level customs data, we aggregate import value by each firm-product-country triplet, i.e., we collect all import transactions for each individual firm that imports a specific HS 6-digit product from a certain source country during each month and aggregate these to one observation as a "firm-product-country" combination. ${ }^{12}$

China's trade volume has increased dramatically since joining the WTO in Dec 2001. China's export and import values in 2000 were approximately 266 billion and 243 billion US dollars, respectively. In 2006, these figures reached 969 billion (increasing by 264\%) and 791 billion (increasing by $226 \%$ ) US dollars. Figure 2(a) presents monthly total import values from Jan 2000 to Dec 2006. The aggregate import value shows a significantly increasing trend over time, especially after accession to the WTO in Dec 2001, although fluctuations are also observed from time to time. To decompose the aggregate import value, we also plot the number of importing firms and the number of product-origin country combinations (see Figures 2(b) and 2(c)). Figure 2 shows that both the number of importing firms and the number of product-country bundles present a steady increasing trend over time, jointly contributing to the phenomenon of soaring aggregate import value after the WTO accession.

\footnotetext{
${ }^{12}$ Note that we adopt HS 6-digit, instead of 8-digit, product classifications to concord them consistently over time based on the conversion table from the UN Comtrade because China adjusts her HS 8-digit product codes occasionally.
} 


\subsection{The margins of China's imports}

It is important to understand the contribution of different margins to trade (e.g., Chaney, 2008; Bernard et al., 2009, among others). We thus follow the method in Bernard et al. (2009) to decompose aggregate import value into different margins and to examine both cross-sectional and time-series variations in China's imports. This decomposition analysis will give us a rough picture of China's imports.

Cross-sectional decomposition - China's aggregate import with partner country $c$ (denoted by $\left.x_{c}\right)$ is decomposed into the number of firms who import from that country $\left(f_{c}\right)$, the number of all products imported from that country $\left(N_{c}\right)$, and the average value of imports per firm-product, $x_{c} /\left(f_{c} N_{c}\right)$. However, it should be noted that the term $x_{c} /\left(f_{c} N_{c}\right)$ is not the intensive margin because the full firm-product bundle $f_{c} N_{c}$ may not all be imported from abroad. Therefore, to account for density of actual trade (Bernard et al., 2009), we will introduce an additional term $d_{c}$, which is defined as the fraction of all possible firm-product combinations that have positive import from partner country $c$, i.e., $d_{c}=o_{c} /\left(f_{c} p_{c}\right)$, where $o_{c}$ is the total number of "firm-product" combinations that have non-zero import value from country $c$. Then, the intensive margin $\bar{x}_{c}$ can be calculated as $x_{c} / o_{c}$. Since firms usually import only a small fraction of the overall products traded, density is typically a positive number ranging from zero to unity and negatively relates to $f_{c}$ and $p_{c}$. We can now decompose import value according to the following equation:

$$
x_{c}=f_{c} p_{c} * \bar{x}_{c} * d_{c}
$$

where $f_{c}$ is the firm-level extensive margin; $p_{c}$ represents the product-level extensive margin; $\bar{x}_{c}$ is the intensive margin; $d_{c}$ is the trade density. The total import value is thus divided into different margins and import density after taking the logarithm on both sides of equation (23).

We then apply a similar decomposition approach as used in Bernard et al. (2009) to compute the relative contribution of each margin to total imports. We regress the logarithm of each trade margin (see the terms on the right-hand side of equation (23)) on the logarithm of total import value on the left-hand side of equation (23). The coefficients sum to unity, with each coefficient representing the share of the overall variation in total import value explained by each margin. For example, the coefficient on $f_{c}$ represents the contribution share of the firm-level extensive margin in explaining the aggregate value of imports. We find that the shares of the aggregate import value being explained by the average firm-level extensive margin, the product-level extensive margin, and the intensive margin are $0.42,0.37$, and 0.53 , respectively, while trade density takes the weight of the remaining -0.35 . If we include two types of extensive margins together, their total contributions outweigh the intensive margin in explaining the variations in aggregate imports. This is consistent with findings in Bernard et al. (2009) using US data. ${ }^{13}$

\footnotetext{
${ }^{13}$ In Bernard et al. (2009), they find that 0.58 of US aggregate import value comes from extensive firm margin, 0.54
} 
Time-series variation - We also follow Bernard et al. (2009) to decompose the time-series variations in Chinese imports between periods. We again decompose total imports onto two types of extensive margins (firm entry and existing and continuing firm additions and deletions of countryproducts) and one intensive margin (continuing firm-product-country growth and decline). Table 1 reports the results and shows that changes in China's imports due to the two types of extensive margins also dominate changes from the intensive margin.

\section{[INSERT TABLE 1]}

\section{Import response to real exchange rate fluctuations}

Now we take a closer look at how real exchange rate fluctuations affect import responses. We investigate firm import responses to exchange rate changes and report results for both the extensive and intensive margins based on micro-level data. In the extensive margin regressions, we further unfold the extensive margin at both the firm and product levels. In the intensive margin, we test both import value and price changes for a specific firm-product-country bundle.

In reality, the importing firm's response in our data set and the exchange rate fluctuations may not occur at the same pace. For example, there is a lag between firm's decisions and import reporting to customs. Also, firms may adjust imports between months to keep the inventory at a constant level. Thus, we test our model predictions for both the short run (monthly intervals) and the long run (quarterly intervals). One might be concerned regarding the monthly short-run analysis due to the seasonal importing behavior of firms. To alleviate this concern, we present a frequency analysis (see Appendix B) and find that most firms import very frequently: more than $71 \%$ of firms import in all twelve months within a year (see Table B.1 in the appendix). Therefore, we are confident in using monthly/quarterly data to examine import response to exchange rate fluctuations. Nonetheless, later in the robustness checks, we will also report results using yearly intervals as the long run.

In our model, an appreciation of the domestic currency implies a reduction of import costs. Consequently, firms tend to enter the importing market and to import more varieties than before. If the elasticity of substitution of imported inputs is high, the increase in import quantity may offset the price reduction, which leads to an increase in import value.

If our prediction is correct, we expect a significant positive coefficient for the exchange rate for both the extensive margins and for importing volume at the intensive margin and a negative coefficient for import price at the intensive margin. Also, this pattern could be more stable over a longer horizon than in the short term due to a time lag in firms' responses.

from product churning, and 0.318 from the intensive margin. 


\subsection{Import responses at the extensive margins}

\subsubsection{Firm entry/exit}

We first test the extensive margin at firm level by examining the effect of exchange rate fluctuations on firms' probability of entry or exit using a probit regression. To be specific, we set the entry and exit dummy as the dependent variable in our regressions. We define entry equaling one if a firm imports in time $t$ but does not import in $t-1$; entry is set to zero if a firm imports in both time $t$ and $t-1$, where time $t$ could be either monthly or quarterly.

As this test is for firm entry/exit probability, the exchange rate is accordingly calculated at firm level, defined as the sum of the weighted exchange rate among all trading partners of the firm. To address the potential endogeneity issue of firm-level exchange rates due to the changing weight of trade partners over time, we adopt two methods for constructing firm-level exchange rates. In both methods for computing the firm exchange rates, the weights for different trade partners are constant over our sample period because we set country weight to be the share of total import value from one country in this firm's aggregate import value from all its trading partners over the entire sample period. Therefore, the constructed firm-level exchange rates alleviate the concern that an importing firm adjusts its trade partners according to exchange rate fluctuations over time. The difference between the two methods is that in the first one, we use the bilateral real exchange rate between RMB and importing countries in our sample to construct firm-level exchange rates. In the alternative, we use real exchange rates only between USD and RMB combined with the constant weight of each trade partner to construct firm-level exchange rates because the majority of Chinese trade transactions are denominated in US dollars.

The regression equation for firm entry is given by

$$
\operatorname{Pr}(\text { Entry }=1)_{i,(t-n, t)}=\Phi\left(\sum_{k=0}^{3} \gamma_{k 1} \Delta e_{i,(t-k-n, t-k)}+\gamma_{z 1} Z_{i t}+\beta_{g 1} g_{t}+F_{i}+F_{t}\right),
$$

where $e_{i t}$ is the firm-level exchange rate fluctuation, $Z_{i t}$ is an export dummy to indicate whether firm $i$ engages in two-way trade (i.e., export and import at the same time interval) and $g_{t}$ is GDP growth to control for demand changes in the domestic market (here, the Chinese market). $F$ represents a set of fixed effect terms, including firm fixed effects $F_{i}$ and time fixed effects $F_{t}$. In the probit regression, we only include time fixed effects, while in the linear probability regressions, we include both firm fixed effects and time fixed effects.

To take into account potentially sluggish import responses to exchange rate shocks, as postulated by the standard arguments for the J-curve response, we exploit the high frequency nature of the data and design the test as follows. The elasticity of the exchange rate $\sum_{k=0}^{3} \gamma_{k 1}$ is the sum of both the contemporaneous coefficient of exchange rate fluctuations (monthly or quarterly) and three lagged coefficients of exchange rate fluctuations. This approach is often used to test price adjustments and 
trade responses to exchange rate fluctuations in the literature, such as Campa and Goldberg (2005); Gopinath, Itskhoki and Rigobon (2010); Gopinath and Itskhoki (2010); Tang and Zhang (2012).

In our test, we distinguish long run and short run responses. We define long run as quarterly changes and short run as monthly changes. In the long-run test, variables (including the entry dummy) capture quarterly adjustment, i.e., $\mathrm{n}=3$. In this case, exchange rate fluctuations $\left(e_{t-k-3, k}\right)$ are quarterly changes covering three months, while in the short-run regression, variables capture monthly adjustments, and exchange rate fluctuations are also defined at monthly basis, i.e., $\mathrm{n}=1$.

Similarly, we test firm exit decisions from importing markets during the period $t$ according to the following equation:

$$
\operatorname{Pr}(E x i t=1)_{i,(t-n, t)}=\Phi\left(\sum_{k=0}^{3} \gamma_{k 2} \Delta e_{i,(t-k-n, t-k)}+\gamma_{z 2} Z_{i t}+\beta_{g 2} g_{t}+F_{i}+F_{t}\right),
$$

where Exit is set to one if firm $i$ imports in time $t-1$ but not in time $t$; it equals zero if firm $i$ continues to import in both time $t$ and $t-1$.

Table 2 shows the baseline regression results for firm entry probability using the weighted firm-level exchange rates. For OECD countries, the coefficients on exchange rate fluctuations are significantly positive across all specifications in both the probit and the linear probability estimations. The positive coefficient suggests that it is more likely for firms to overcome fixed costs and to import from abroad when the domestic currency appreciates. The net coefficient for the long run is obtained by adding coefficients over four smooth-moving regressions; similarly, the short-run coefficient is the sum of monthly coefficients over four continuing monthly regressions. In contrast, the significantly negative coefficients for firm exit suggest that it is unlikely that firms exit from the importing market when facing domestic currency appreciation. The results here are consistent with Proposition 1 in our model. We also calculate the marginal effect of exchange rate fluctuations on import decisions of firm entry/exit. In the long run, a 10 percent RMB appreciation improves the probability of firm entry by 0.02 percent and reduces probability of exit by 0.02 percent for OECD countries. In the short run, the probability of entry increases by 0.007 percent and the probability of firm exit reduces, though not significantly, by 0.04 percent for imports from OECD countries.

\section{[INSERT TABLE 2]}

In Table 3, we report the results using the alternative approach with only USD/RMB exchange rate to calculate firm-level exchange rates. In the long run, the marginal effect of real exchange rate fluctuations shows that a 10 percent real appreciation of RMB against USD improves the probability of firm entry by 0.05 percent and reduces the probability of exit by more than 0.32 percent for imports from OECD countries. In the short run, the effects are less significant but still show the predicted signs as in Proposition 1. Compared with results in Table 2, the two approaches in computing firmlevel exchange rates yield similar results, and the only difference is that the coefficients are larger in 
the second test than in the one using weighted firm-level exchange rates. Generally speaking, the firm-level extensive margin responses follow our predictions (see Proposition 1) in both the long run and the short run, which contributes to the aggregate increase of import value after domestic currency appreciation.

\section{[INSERT TABLE 3]}

\subsubsection{Products adding/dropping}

According to the model prediction in Proposition 2, firms add more product varieties into the import set or import from more foreign countries while they eliminate fewer product varieties or stop importing from fewer countries when facing a domestic currency appreciation. We thus test products adding and dropping using probit and linear probability regressions similar to the previous tests for firm entry/exit. We classify product variety at the HS 6-digit level, and define HS-6 products from different originating countries as different varieties. In other words, according to the HS-6 product and the country origin, we construct a new "product-country" bundle to test the product churning effect. We use the following regression equations:

$$
\begin{gathered}
\operatorname{Pr}(A d d=1)_{i h c(t-n, t)}=\Phi\left(\sum_{k=0}^{3} \eta_{k 1} \Delta e_{c,(t-k-n, t-k)}+\eta_{z 1} Z_{i t}+\eta_{g 1} g_{t}+F_{i h c}+F_{t}\right) \\
\operatorname{Pr}(\operatorname{Drop}=1)_{i h c,(t-n, t)}=\Phi\left(\sum_{k=0}^{3} \eta_{k 2} \Delta e_{c,(t-k-n, t-k)}+\eta_{z 2} Z_{i t}+\eta_{g 2} g_{t}+F_{i h c}+F_{t}\right)
\end{gathered}
$$

where $i, h, c, t$ represent firm, HS6 product, country and time (month or quarter), respectively. $\Delta e_{c t}$ represents real exchange rate changes between country $c$ and domestic country at time $t$. We use the dummy variables $A d d$ or Drop to capture firm $i$ 's adding/dropping a specific product $h$ from country $c$ at time $t$. To be specific, $A d d$ equals one if a product appears in period $t$ but not in previous period $t-1$, and zero otherwise; Drop equals one if a product appears in period $t-1$ but not in period $t$. For control variables, we include the two-way trade dummy $Z_{i t}$ and the GDP growth rate $g_{t}$ to control for domestic demand. Firm-product-country fixed effects and year fixed effects are also included in the linear probability regression.

\section{[INSERT TABLE 4]}

The results at both quarterly and monthly intervals are reported in Table 4 . In columns 1 and 2 of Table 4, we notice that a rise in real exchange rates (real appreciation of domestic currency) has a positive impact on products adding. In columns 3 and 4 , there are significantly negative coefficients on exchange rates for products dropping regressions. The result suggests that, similar to the firmlevel extensive margin test, an appreciation of local currency leads to an increase in the probability of 
adding imported products and a decrease in the probability of dropping imported products. Columns 5-8 report the results using a linear probability estimation. The results support the model predictions on products adding/dropping as stated in Proposition 2.

\subsection{Import responses at the intensive margin}

To test the impact of exchange rate fluctuations on the intensive margin, we estimate the following two specifications:

$$
\begin{aligned}
\Delta x_{i h c(t-n, t)} & =\sum_{k=0}^{3} \beta_{k 1} \Delta e_{c,(t-k-n, t-k)}+\beta_{z 1} Z_{i t}+\beta_{g 1} g_{t}+F_{i h c}+F_{t}+\epsilon_{i h c t} \\
\Delta p_{i h c(t-n, t)} & =\sum_{k=0}^{3} \beta_{k 2} \Delta e_{c,(t-k-n, t-k)}+\beta_{z 2} Z_{i t}+\beta_{g 2} g_{t}+F_{i h c}+F_{t}+\epsilon_{i h c t}
\end{aligned}
$$

where $i, h, c, t$ represent firm, HS6 product, country and time (month or quarter), respectively. $x_{i h c t}$ represents the logarithm of the import value of product $h$ by firm $i$ from country $c$ at time $t$, and $e$ is the logarithm of the real exchange rate between the RMB and importing country c's currency at time $t$. $g_{t}$ is the GDP growth rate at time $t$ to control for demand shift in the domestic market. $F$ is the set of fixed effect terms. We add fixed effects at firm-country-product level $F_{i h c}$ and year level $F_{t}$. $\epsilon_{\text {ihct }}$ denotes unobserved shocks.

In the second specification (see equation (27)), we focus on the effect of real exchange rate fluctuations on domestic import price changes. The dependent variable becomes $\Delta p_{i h c t}$, the price change of product $h$ imported from country $c$ by firm $i$ during time $(t-n, t)$. Import prices have been converted into RMB prices using monthly spot rates. The independent variables are the same as in the regression for import value. ${ }^{14}$

The baseline regression results for the intensive margin are reported in Table 5. Columns 1-4 report the import value (see columns 1 and 3) and import price (see columns 2 and 4) regression for imports from all OECD countries. Columns 5 and 6 report results for the import value from the US in both the long run and the short run.

\section{[INSERT TABLE 5]}

Table 5 shows that the coefficients for the accumulative effect within the long run are significantly positive for imports from OECD countries (see column 1). This suggests that from a longer time perspective, the average import value from the OECD for a current "firm-product-country" triplet increases by 5.3 percent under a 10 percent RMB real appreciation. The effect is robust after controlling

\footnotetext{
${ }^{14}$ Because we are using monthly panel data, we perform a Dickey-Fuller test for the stationarity of RMB fluctuations with the trading partners' currency. The $p$ value suggests that we reject the null hypothesis of a unit root for both monthly and quarterly changes in exchange rates at all common significance levels in our sample. Thus, we do not use the VEC estimation as in a typical time-series analysis.
} 
for fixed firm-product-country and time fixed effects. This is consistent with Proposition 3 that the intensive margin of imports, i.e., the expenditure for each imported variety, increases when domestic currency appreciates. For import price changes, if the local currency appreciates, the representative price of imports in terms of local currency should be reduced. As shown in Table 5, in the long run, the import price for imports from OECD countries reduces by 0.57 percent under a 10 percent RMB appreciation (see column 2).

In the short run, when we look at the coefficients for accumulative responses, the results at the intensive margin are less robust. To be specific, import value even decreased slightly by 0.6 percent in the short run under a 10 percent real appreciation (see column 3), which contradicts our prediction. Since the import responses to exchange rate shocks may have time lag, it is not surprising that the short-run effect is less robust than that for the long run. However, the price response in the short run remains significantly negative which is consistent with the results in the long run (see column 4). For import values from the US (see columns 5 and 6), we observe that the intensive margin rises by 7.8 percent in the short run and by 4.5 percent in the long run under a 10 percent appreciation of the local currency.

\subsection{Changes in margins and exchange rate fluctuations}

So far, we have tested each type of import margin separately using Chinese data that support Proposition 1-3. Now, we present fluctuations in the different margins and aggregate import value together in Figure 3. Intuitively, all fluctuations follow the same trend and aggregate import value fluctuation dominates. This result suggests that changes in both the extensive and intensive margins contribute to aggregate import value fluctuation. To quantitatively test the response of different import margins to real exchange rate fluctuations, we use a simple regression at a monthly basis to estimate the response of changes in each margin across trade partners with respect to exchange rate fluctuations. ${ }^{15}$ We first distinguish import value and different margins of imports to obtain the changes in (1) total import value, (2) firm margin, (3) product-country margin, and (4) intensive margin. To be specific, the change in the firm-level extensive margin represents the net entry out of exit in a given month; similarly, the change in the product-level extensive margin represents the net number of products added out of those dropped. The change in the intensive margin is the adjustment of the import value for each "product-country" bundle of existing import firms in our sample.

Table 6 reports the results from regressing the first difference (monthly) of firm number, products and intensive margins on exchange rate changes. Column 1 of Table 6 shows the coefficient of real exchange rate fluctuations for changes in the aggregate import value, columns 2 and 3 report those for changes in the number of firms and the number of products, and the last column is for changes in the intensive margin fluctuations. After controlling for country fixed effects, we find that exchange rate

\footnotetext{
${ }^{15}$ The sample size for this regression is 2205 country-month observations, which is an unbalanced panel.
} 


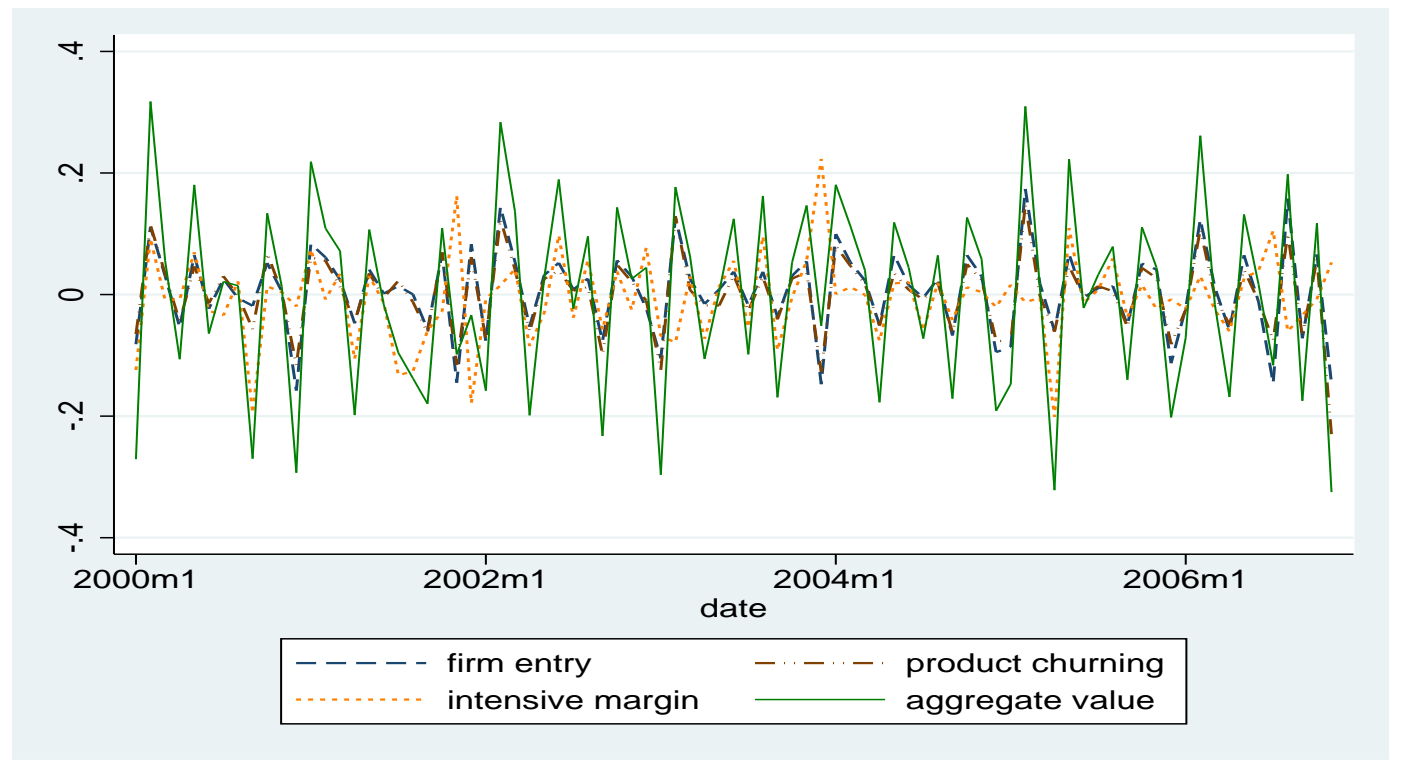

Figure 3: Fluctuations in margins of import over time

fluctuations play a significant role in determining firm entry and product churning, which leads to an overall increase in import value. A one percent real appreciation of currency significantly increases the probability of entry by 0.23 percent and products adding by approximately 0.24 percent. But real exchange rate fluctuations have an insignificant positive coefficient on the intensive margin. The insignificant coefficient for the intensive margin suggests an insignificant increase in the import value by continuing importers. To conclude, although all margins of import contribute to the aggregate increase in import value, the extensive margins rather than intensive margin are the major contributors to the aggregate import response to real exchange rate fluctuations in China. ${ }^{16}$

\section{Robustness}

\subsection{A yearly long-run investigation}

Previously, we focus on firms' responses including entry/exit and product churning mainly at monthly and quarterly basis. According to an import frequency analysis in Table B.1 in Appendix B, the majority of importers continuously import during most of months within a year, and they also import the same product (or major product) consistently for many months within one year. However, one might still concern about some seasonal importers. Because those seasonal production activities may yield a continuing cease of importing for successive months within a year, for which case it may be treated as firm exit or product dropping. To exclude this concern, we conduct a yearly regression to

\footnotetext{
${ }^{16}$ This is different from findings in other studies regarding importers' response to exchange rate changes in small open economies, as suggested in Lu, Mariscal and Mejia (2012). Other studies show that the intensive margin (including product switching, i.e., both adding and dropping products, within firms) is the most important pattern when Columbian importers face a large real appreciation.
} 
capture firms' responses at a longer horizon.

In this exercise, we examine yearly import value changes instead of quarterly as a long-run intensive margin test. Also, at extensive margin levels, if a firm imports at least once within a year we treat it as a non-exit importer; if a product-country bundle appears at least once within a year, we treat it as a non-dropping product-country bundle. Exchange rates between origin country and China are computed as average real exchange rates at yearly basis.

The results of yearly regressions are presented in Table 7. Extensive margin at firm level is reported in columns $1-4 ;^{17}$ extensive margin at product-country level is in columns 5-8; and intensive margin is displayed in columns 9-11. Following a similar approach as in previous analysis, we use both probit and linear probability regressions to test extensive margin adjustment and linear regressions with fixed effects for intensive margin test. ${ }^{18}$ We find that all responses (e.g., firm entry/exit, product adding/dropping and import value changes) follow the same pattern as in the previous tests. Firms increase entry or product adding probability and import value under a domestic currency appreciation, while reduce exit or product dropping probability at the same time. Thus, our model predictions are also supported by a long-run yearly investigation.

\section{[INSERT TABLE 7]}

\subsection{Subsample: Ordinary Trade vs. Processing Trade}

One of the distinctive features of Chinese trade is that importers often engage in global value chain. Those importers use imported intermediate inputs for production and then sell products to foreign partners. A possible trade pattern is that Chinese importers may import raw and auxiliary materials, parts and components, accessories or materials from abroad, and re-export the finished products after processing or assembly. Hence, compared with ordinary trade, processing trade firms may respond differently to exchange rate changes. In this section, we separate all transactions into two categories: processing trade and ordinary trade. Here we do not distinguish "pure assembling" and "processing with imported materials" (or input and assembly), and label both types as "processing trade". In the test, we re-check responses of intensive and extensive margins to exchange rate fluctuations for both ordinary trade and process trade transactions.

The results for product-level extensive margin are reported in Table 8. Columns 1-4 present results for ordinary trade, while columns 5-8 display results for processing trade. The most significant difference between ordinary trade and processing trade exists in the response of product extensive margin, i.e., the effect of exchange rate appreciation on product-country churning. In Table 8, for

\footnotetext{
${ }^{17}$ Here we only use the first approach of computing firm-level exchange rates to test yearly responses based on bilateral real exchange rates between China and partner countries due to the lack of variations in yearly real exchange rates between USD and RMB.

${ }^{18}$ For the import price test in Table 7 , we use RMB denominated prices based on yearly nominal exchange rates between USD and RMB from World Bank.
} 
the long run, the probability of adding imported products decreases for processing trade under RMB appreciation, which is opposite with a positive coefficient for ordinary trade presented in the left panel. Intuitively, for processing trade importers, a decreasing marginal benefit of exporting offsets an increase in marginal benefit of import due to a reduction in importing input costs. In this way, a predicted positive stimulating effect of currency appreciation for importing certain varieties by ordinary trade importers is not guaranteed for those who engage in global value chain. Due to the existence of hybrid firms (defined as firms who involve both processing and ordinary trade simultaneously for different products), it is more meaningful to test extensive margin difference between processing and ordinary trade at product-country level than firm level. Nevertheless, we still check extensive margin at firm level in our test which are presented in Table 9 where we use a weighted firm-level exchange rate as in the previous tests to evaluate firm entry/exit probability with exchange rate fluctuations. As expected, the predicted responses for processing trade are weaker and even display opposite pattern.

\section{[INSERT TABLES 8 and 9]}

For the intensive margin test (see Table 10), the coefficients of exchange rate are similar for both ordinary and processing trade in the long run. However, in the short run, unlike ordinary trade, exchange rate coefficient of processing trade decreases under a currency appreciation. For import price, we find that import price reduces when RMB appreciates in short run for both types of trade. In the long run, the magnitude of price decline for processing trade is larger than that of ordinary trade.

\section{[INSERT TABLE 10]}

In summary, compared to ordinary trade, the import responses to exchange rate fluctuations under processing trade are weaker or even ambiguous. This finding is consistent with our theoretical prediction in Proposition 4.

\section{$7 \quad$ Further discussions}

\subsection{Different stages in exchange rate regime switching}

Although China's exchange rate regime reforms and RMB appreciation have occurred since July 2005, the reforms can be divided into several phases. Before early 2003, China adopted a firmly pegged US dollar exchange rate policy, and there was no foreseen reform in China's exchange rate policy.

In early February 2003, in the G7 meeting, Japan proposed a reform in China's exchange rate policy. After that point, there was much debate and many discussions about the necessity and feasibility of exchange rate reform in China. The Chinese government hence faced increasing pressure from western society to reform its exchange rate policy. For example, in September 2003, during a visit by the 
Secretary of the Treasury of the US to China, a less government-interventionist exchange rate policy was required as a move toward a free-floating exchange rate regime. In the G7 meeting in 2004, more countries and global institutions including the IMF started demanding that China adopt a floating exchange rate policy to replace the previously fixed one. Western countries believed that the RMB had been severely undervalued, which led to a huge trade surplus for China. Starting in 2003, the foreign currency market also anticipated an appreciation of the RMB. The forward exchange rate between the USD and the RMB well reflected the market's expectation because the forward rate started to appreciate in late 2003. The president of the China Central Bank at the Boao Forum for Asia in May 2005 also announced that an exchange rate reform would be listed on the agenda.

It was believed that a reform was certainly coming. But there was still uncertainty about when and how this reform would be enacted: a steady appreciation or an abrupt adjustment? This discussion lasted until July 2005, when the Chinese government announced that China would follow a managed floating exchange rate with the RMB pegged against a basket of currencies instead of the US Dollar, although the basket composition and weight was never revealed. Since then, the RMB has been steadily appreciating against the USD. ${ }^{19}$

Although a reform in the exchange rate regime was announced in July 2005, the change was not a one-time shock. We can actually divide the period from 2000-2006 into three phases. The first phase is from 2000 to late 2003, during which there was neither change nor any expectation of a change in the exchange rate policy. The second phase lasted from Q4 of 2003 to July 2005, when the debate regarding exchange rate reform was heated and the market expected an appreciation of RMB/USD in the near future. The last phase started in July 2005, when exchange rate reform was officially announced. Obviously, with changes in the expectations for subsequent appreciation, firms responded differently during each phase of the reform. Therefore, we explore the differences in firms' import responses under each phase. Three phase dummies are constructed to indicate the three phases of regime switching during China's exchange rate reform between 2000 and 2006.

We test the following specification by including the three phase dummies to capture different phases in China's exchange rate reform. $R_{i}$ is the set of regime dummies for $\left\{R_{1}, R_{2}, R_{3}\right\}$, corresponding to the three different phases in our sample. $\Delta y_{i h c t}$ is the import response for firm $i$ importing product $h$ from country $c$ at time $t$ (including product-country adding/dropping in the extensive margin test and import value/price in the intensive margin test). Then we interact the real exchange rate fluctuations with those three dummies to investigate their respective effects on import responses:

$$
\Delta y_{i h c t}=\Delta e_{c t} * R_{1}+\Delta e_{c t} * R_{2}+\Delta e_{c t} * R_{3}+F_{i h c}+F_{t}+\varepsilon_{i h c t}
$$

We test response at the intensive margin as well as the extensive margins to real exchange rate

\footnotetext{
${ }^{19}$ The only exception was during 2008-2010, when the RMB was de facto pegged to the USD. Nevertheless, the other periods have been dominated by the steady appreciation of the RMB.
} 
fluctuation under different regimes. Table 11 shows the extensive margins at the "product-country" level, and Table 12 lists results for the intensive margin. ${ }^{20}$

Table 11 displays the extensive margin response to the real exchange rate fluctuations under different regimes. As in previous tests, we use both probit in columns 1-4 and linear probability regressions in columns 5-8 to test the probability of adding/dropping products. We find that firms tend to adjust product-country bundles mostly under regimes 2 and 3, i.e., the expected and confirmed exchange rate regimes. This pattern clearly holds in the quarterly test, but becomes ambiguous in the monthly test. These results suggest that under appreciation stages, either expected or confirmed, favorable exchange rate fluctuations encourage firms to import more varieties or to import from more countries. This extensive margin adjustment occurs through adding and dropping product-country bundles within firms.

Table 12 shows the intensive margin response to exchange rate fluctuations under different regimes. Columns 1-3 show the quarterly response, while columns 4-6 show the monthly response. Columns 1 , 3, 4 and 6 are for import values and columns 2 and 5 refer to import price. We present results for both OECD countries and the US when testing the intensive margin regarding import value. We find that under regime 1, i.e., the fixed exchange rate regime, the import value responses are the most obvious among all three regimes in both the long and short run. Import value increases significantly less in regime 2 and even decreases in regime 3 in the long run. For the import price response, there is little difference between regimes in the short run, which indicates that in the short run, regime shifts do not much influence import price adjustments. Again, all import prices are converted into RMB prices for the import price test. In the long run, the import price reduces most during the first and third regimes, which are either confirmed fixed or confirmed appreciation stages. For imports from the US, the import value also responds to the exchange rate most in regime 1 . The above finding suggests that firms are more willing to adjust import value according to real exchange rate fluctuations under a fixed exchange rate regime. Under such a fixed exchange rate regime without uncertainty, importers adjust the import value of the imported varieties to respond to exchange rate fluctuations in a more predictable way.

[INSERT TABLES 11 and 12]

Now we summarize the patterns related to the above results. First, in the short run, firms' responses to exchange rate changes show a lack of variation between different stages during the reform. Second, in the long run, firms display significantly different responses at the extensive margin during different stages of the reform. Continuing importers tend to adjust the "product-country" under both the expected and the confirmed appreciation stages, which lasted from late 2003 to 2006 . Third,

\footnotetext{
${ }^{20}$ Because firms' entry/exit decisions cover longer time intervals (usually lasting years), our regime regression for the extensive margin at firm level may not accurately capture the different responses under various phases. Thus, we mainly focus on the intensive margin test and on the extensive margin at product level.
} 
also in the long run, firms display various responses in the intensive margin under different stages of reform. Under a fixed exchange rate regime (2000-early 2003), importers behave the most responsively to exchange rate fluctuations. But in phases 2 and 3, this responsiveness diminished substantially. In terms of import price, we find little difference under the different stages in the short run; but in the long run, import price is more likely to adjust in response to exchange rate fluctuations under a fixed exchange rate regime. Our findings suggest that firms do respond differently to exchange rate shocks when facing uncertainties about exchange rate regime changes.

\subsection{Exchange Rate Pass-through to Import Price}

Import price elasticity to the exchange rate, which is also known as the pass-through of the exchange rate, is one of the most important issues in the literature. In this section, we test the pass-through of nominal exchange rates between China and OECD countries to product price by using this highly disaggregate-level data. ${ }^{21}$ Our product price, computed as a unit value using the total value divided by the total quantity, is calculated at the HS 6-digit level. Because the import value in the customs data is denominated in USD, our price (value per unit) has been transferred into RMB using monthly spot exchange rates of RMB/USD .

Using a rolling window regression similar to that in in Gopinath and Itskhoki (2010), we test both the short-run (within 3 months) and the long-run (within 12 months) pass-through of exchange rate fluctuations. Our results are presented in Figure 4(a) and 4(b) for both short-run and long-run pass-through. In the short run, we notice that the elasticity within three months is quite small, at approximately 0.12 to $0.22 .^{22}$ This suggests that, in the short run (quarterly or monthly), this passthrough effect is highly incomplete. In the long run (yearly), we find that the elasticity value rises to approximately 0.50 to 0.75 . This suggests that the pass-through of exchange rates to import price has an accumulative effect, and the elasticity coefficients gradually grow towards a larger value, although the one-year elasticity is still incomplete in our test.

If we further investigate elasticity value over a longer time interval, we find that both short-run and long-run pass-through presents a declining pattern over time. This pattern is more obvious in the long run than in the short run. The pass-through elasticity is reduced from 0.75 in 2000 to approximately 0.5 in 2006. Although pass-through in the short run is volatile, the value still shifts down towards a smaller value.

Both the incomplete and the declining patterns of pass-through are also found among developed countries and are documented in Campa and Goldberg (2005) and Marazzi and Sheets (2007). The former finds incomplete pass-through to import price for major developed countries, while the latter use a reduced form analysis and find that pass-through elasticity is declining over time for the US.

\footnotetext{
${ }^{21}$ Because before 2005, China had adopted a pegged-to-USD exchange rate policy, we drop observations between the US and China before July 2005 for a constant nominal exchange rate between USD/RMB.

${ }^{22}$ We also test the import price pass-through within one month; the elasticity is approximately 0.02-0.03.
} 


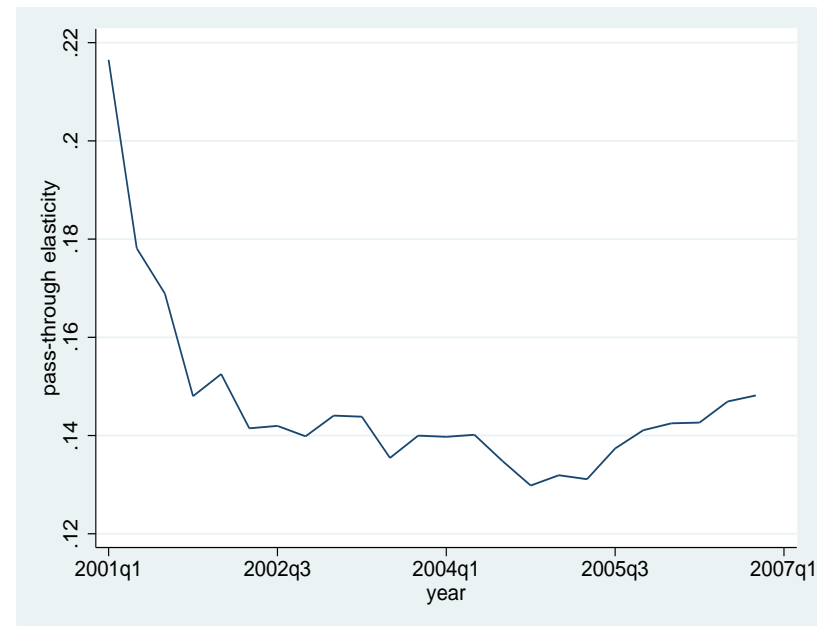

(a) Pass Through of Import Price in Short Run: 3-month

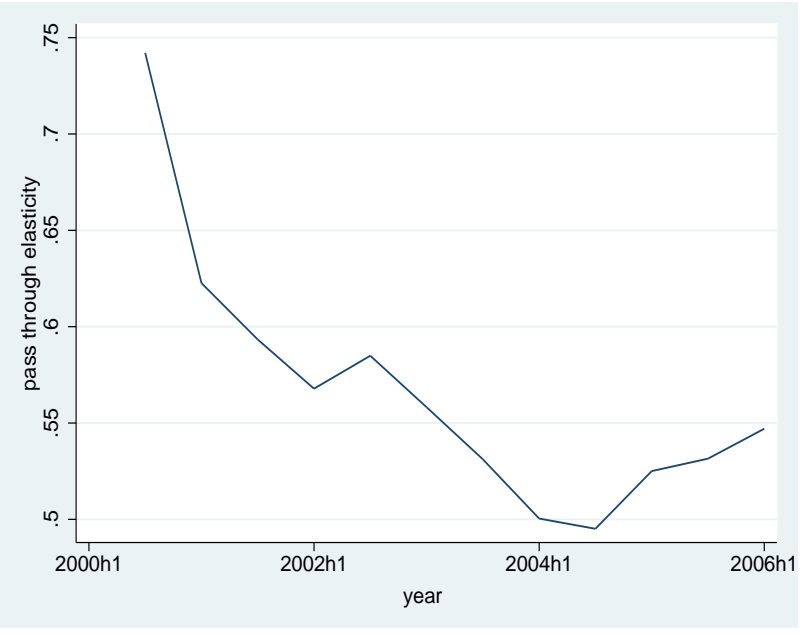

(b) Pass Through of Import Price in Long Run: 1-year

Here, we find that those patterns also exist for Chinese imports.

\section{Conclusion}

In this paper, we use micro-level data to investigate firms' import responses to real exchange rate fluctuations, addressing the RMB exchange rate reform. After decomposing the changes in imports, the extensive margin, classified as both firm entry/exit and product adding/dropping, contributes to a substantial part of the overall changes in aggregate imports. This suggests that more firms participate in import activities, and once they start importing, they tend to import more varieties and more value when domestic currency appreciates. The drastic rise in the number of importers or the imported product varieties are the main force driving China's aggregate import value upward during 2000-2006. The predicted pattern is more significant for ordinary trade than for the processing trade. Those patterns are explained by our heterogeneous-firm trade model, and the empirical investigations support the model predictions. Also, there is an incomplete pass-through effect on the import price and a declining pattern for the elasticity of pass-through over time. Moreover, there exist variations among firms' responses to exchange rate fluctuations under the transition of exchange rate regimes, namely, from a fixed exchange rate regime, to an expected appreciation regime and finally to a confirmed appreciation regime.

A potential direction for future research would be the heterogeneous response of firms to exchange rate fluctuations, including firm productivity, financial status and ownership. Previous studies of a similar topic only focus on the export side. For example, Berman, Martin and Mayer (2012) and Li et al. (2012) find that high-productivity firms have lower pass-through and more price-to-market behavior in exporting. But the import response is less studied. In addition, other heterogeneous firm characteristics (e.g., financial status, ownership) may also contribute to explaining the heterogeneity 
in firms' import responses to exchange rate shocks and incomplete exchange rate pass-through.

\section{References}

Ahmed, Shaghil. 2009. "Are Chinese exports sensitive to changes in the exchange rate?"

Amiti, Mary, Oleg Itskhoki, and Jozef Konings. 2012. "Importers, Exporters, and Exchange Rate Disconnect." National Bureau of Economic Research, Inc NBER Working Papers 18615.

Arkolakis, Costas. 2010. "Market Penetration Costs and the New Consumers Margin in International Trade." Journal of Political Economy, 118(6): 1151 - 1199.

Berman, Nicolas, Philippe Martin, and Thierry Mayer. 2009. "How do different exporters react to exchange rate changes? Theory, empirics and aggregate implications." , (7493).

Berman, Nicolas, Philippe Martin, and Thierry Mayer. 2012. "How do Different Exporters React to Exchange Rate Changes?" The Quarterly Journal of Economics, 127(1): 437-492.

Bernard, Andrew B., J. Bradford Jensen, Stephen J. Redding, and Peter K. Schott. 2009. "The Margins of US Trade." American Economic Review: Papers and Proceedings, 99(2): 487-93.

Campa, Jose Manuel, and Linda S. Goldberg. 2002. "Exchange rate pass-through into import prices: a macro or micro phenomenon?"

Campa, Jos Manuel, and Linda S. Goldberg. 2005. "Exchange Rate Pass-Through into Import Prices." The Review of Economics and Statistics, 87(4): 679-690.

Chaney, Thomas. 2008. "Distorted Gravity: The Intensive and Extensive Margins of International Trade." American Economic Review, 98(4): 1707-21.

Cheung, Yin-Wong, Menzie D. Chinn, and Eiji Fujii. 2010. "China's Current Account and Exchange Rate." In China's Growing Role in World Trade. NBER Chapters, 231-271. National Bureau of Economic Research, Inc.

Dayal-Gulati, Anuradha, and Valerie Cerra. 1999. "China's Trade Flows-Changing Price Sensitivies and the Reform Process." International Monetary Fund IMF Working Papers 99/1.

Dees, Stephane. 2001. "The opening policy in China: Simulations of a macroeconometric model." Journal of Policy Modeling, 23(4): 397-410.

Dong, Wei. 2012. "The role of expenditure switching in the global imbalance adjustment." Journal of International Economics, 86(2): 237-251.

Eaton, Jonathan, Samuel Kortum, and Francis Kramarz. 2011. "An Anatomy of International Trade: Evidence From French Firms." Econometrica, 79(5): 1453-1498. 
Garcia-Herrero, Alicia, and Tuuli Koivu. 2009. "Chinas exchange rate policy and Asian trade." BIS Working Papers, , (282).

Gopinath, Gita, and Brent Neiman. 2014. "Trade Adjustment and Productivity in Large Crises." American Economic Review, 104(3): 793-831.

Gopinath, Gita, and Oleg Itskhoki. 2010. "Frequency of Price Adjustment and Pass-Through." The Quarterly Journal of Economics, 125(2): 675-727.

Gopinath, Gita, Oleg Itskhoki, and Roberto Rigobon. 2010. "Currency Choice and Exchange Rate Pass-Through." American Economic Review, 100(1): 304-36.

Hummels, David, and Peter J. Klenow. 2005. "The Variety and Quality of a Nation's Exports." American Economic Review, 95(3): 704-723.

Koopman, Robert, Zhi Wang, and Shang-Jin Wei. 2012. "Estimating domestic content in exports when processing trade is pervasive." Journal of Development Economics, 99(1): 178-189.

Lau, Francis, Yik-ko Mo, and Kim-hung Li. 2004. "The Impact of a Renminbi Appreciation on Global Imbalances and Intra-Regional Trade." Hong Kong Monetary Authority Quarterly Bulletin, $16-26$.

Liao, Wei, Kang Shi, and Zhiwei Zhang. 2012. "Vertical trade and China's export dynamics." China Economic Review, 23(4): 763-775.

Li, Hongbin, Hong Ma, Yuan Xu, and Yanyan Xiong. 2012. "How do exchange rate movements aect Chinese exports? A firm-level investigation."

Lu, Dan, Asier Mariscal, and Fernando Mejia. 2012. "Imports Switching and the Impact of Large Devaluation."

Manova, Kalina, and Zhiwei Zhang. 2012. "Export Prices Across Firms and Destinations." The Quarterly Journal of Economics, 127(1): 379-436.

Marazzi, Mario, and Nathan Sheets. 2007. "Declining exchange rate pass-through to U.S. import prices: The potential role of global factors." Journal of International Money and Finance, 26(6): 924-947.

Marquez, Jaime, and John Schindler. 2007. "Exchange-rate Effects on China's Trade." Review of International Economics, 15(5): 837-853.

Tang, Heiwai, and Yifan Zhang. 2012. "Exchange Rates and the Margins of Trade: Evidence from Chinese Exporters." CESifo Economic Studies, 58(4): 671-702. 
Thorbecke, Willem, and Gordan Smith. 2012. "ARE CHINESE IMPORTS SENSITIVE TO EXCHANGE RATE CHANGES?" China Economic Policy Review, 01(02): 1250012.

Thorbecke, Willem, and Gordon Smith. 2010. "How Would an Appreciation of the Renminbi and Other East Asian Currencies Affect China's Exports?" Review of International Economics, 18(1): 95-108.

Xing, Yuqing. 2011. "Processing Trade, Exchange Rates and Chinas bilateral Trade Balances." National Graduate Institute for Policy Studies GRIPS Discussion Papers 10-30.

Yu, Miaojie. 2009. "Revaluation of the Chinese Yuan and triad trade: A gravity assessment." Journal of Asian Economics, 20(6): 655-668.

Yu, Miaojie. 2010. "Processing Trade, Firm's Productivity, and Tariff Reductions : Evidence from Chinese Products." East Asian Bureau of Economic Research Macroeconomics Working Papers 22799 . 


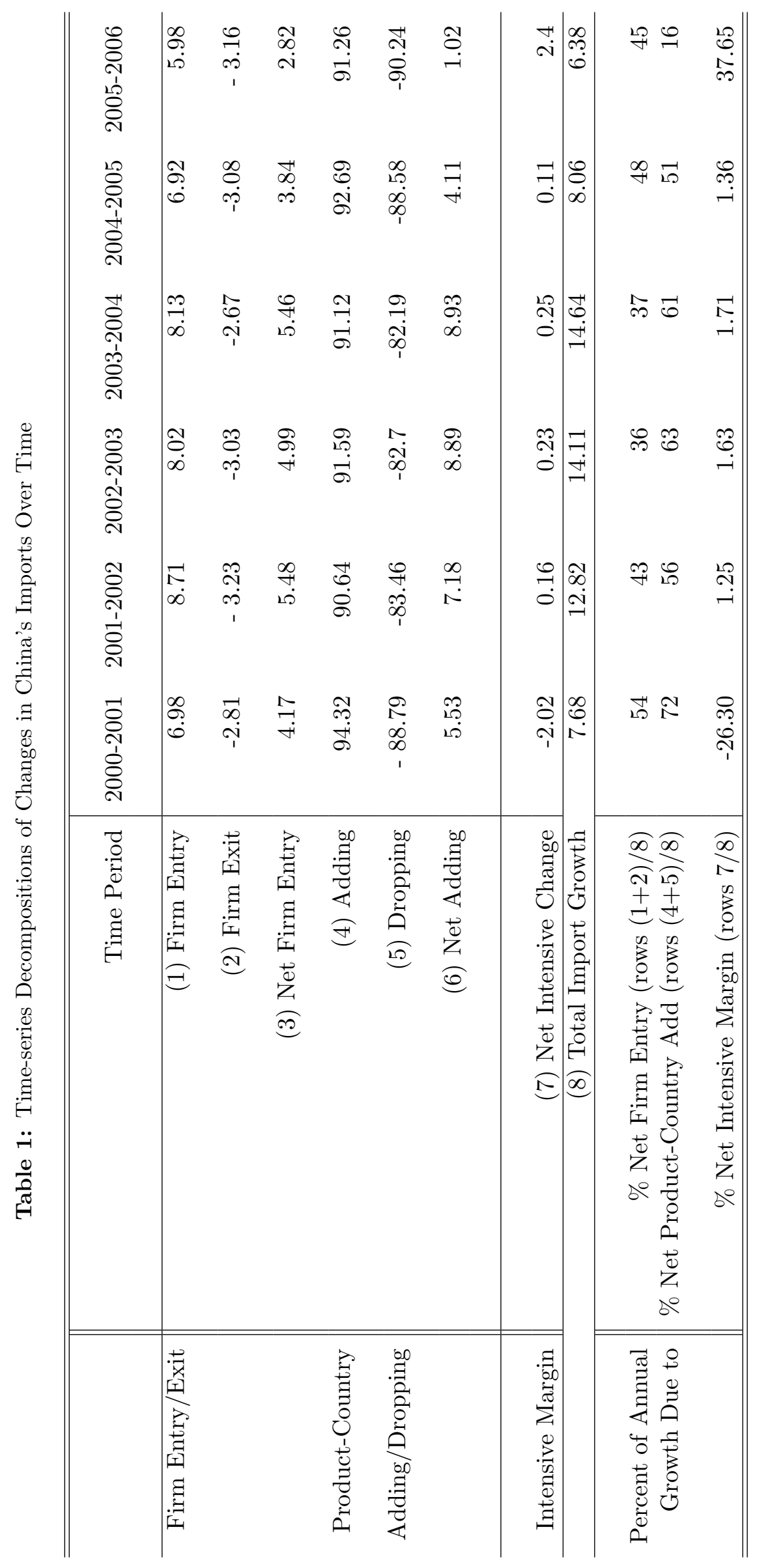




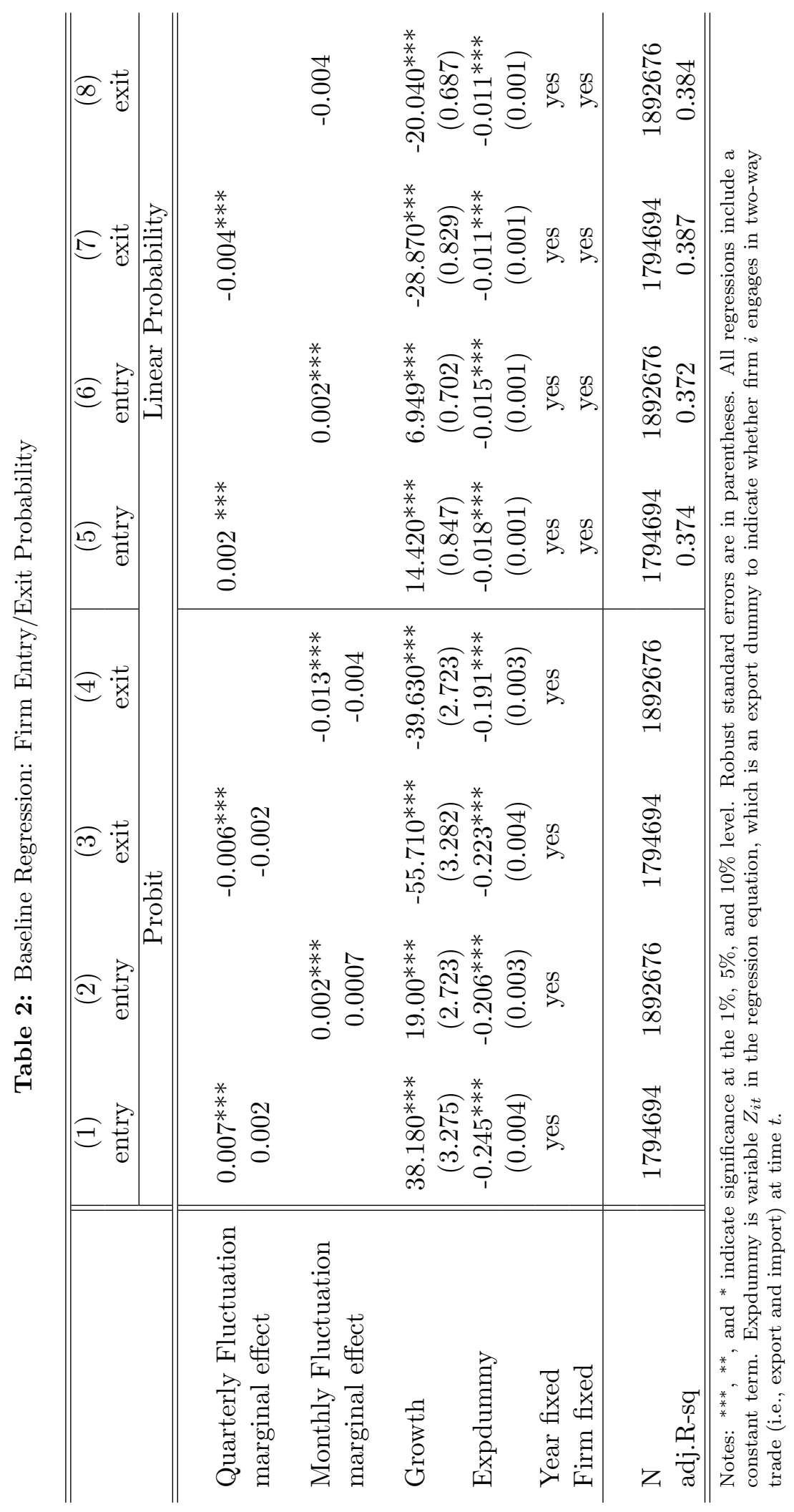




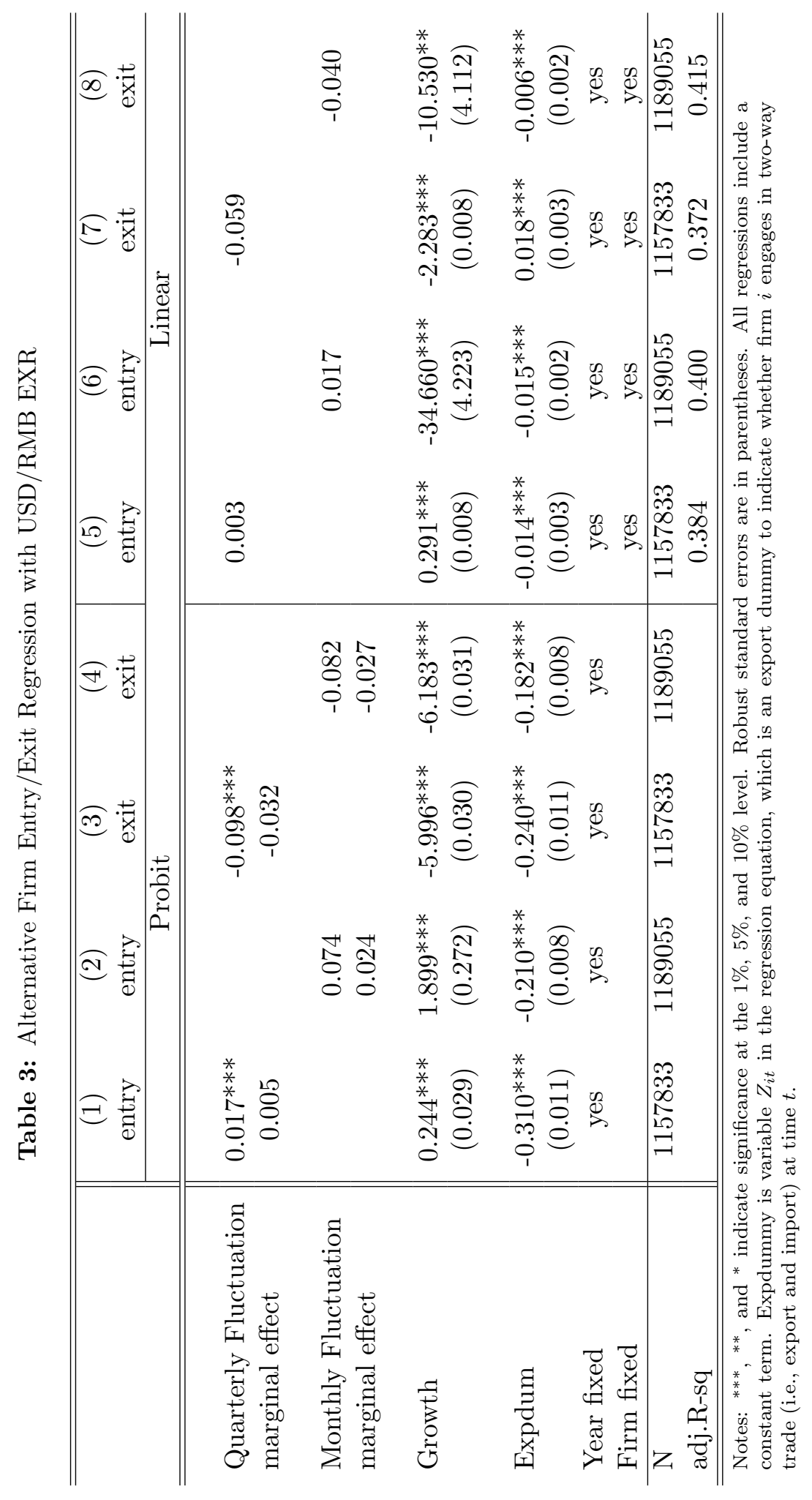




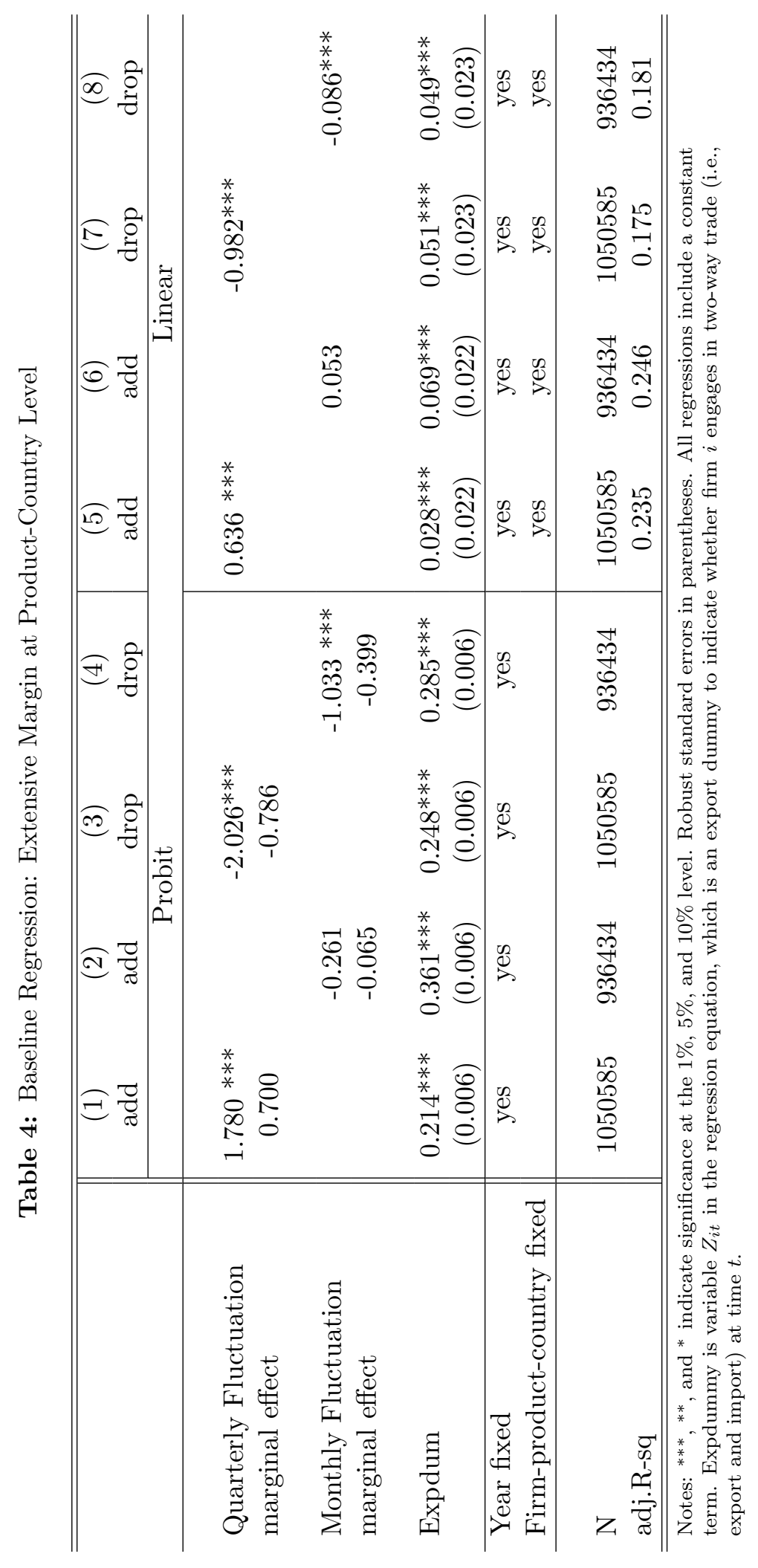




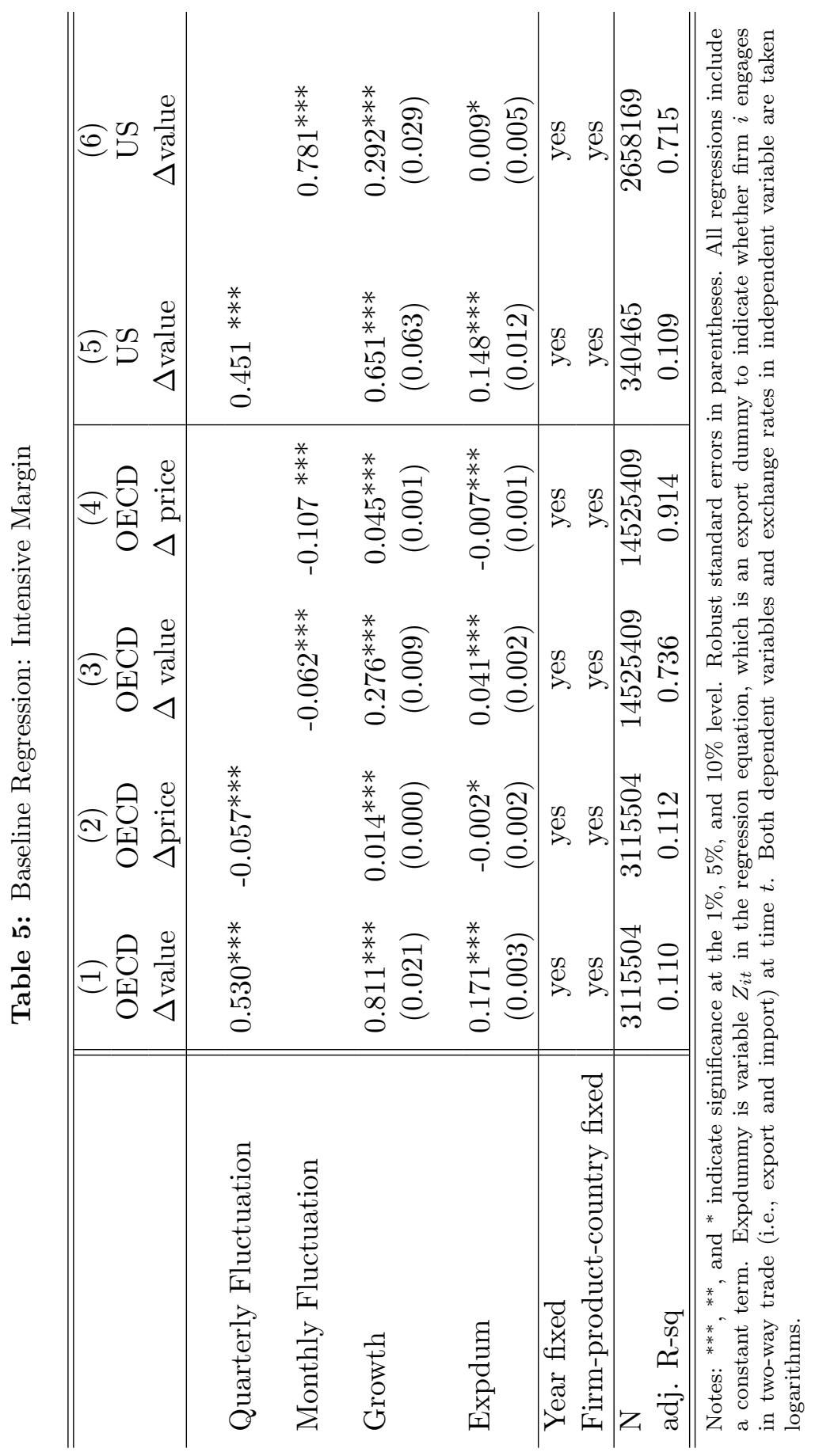




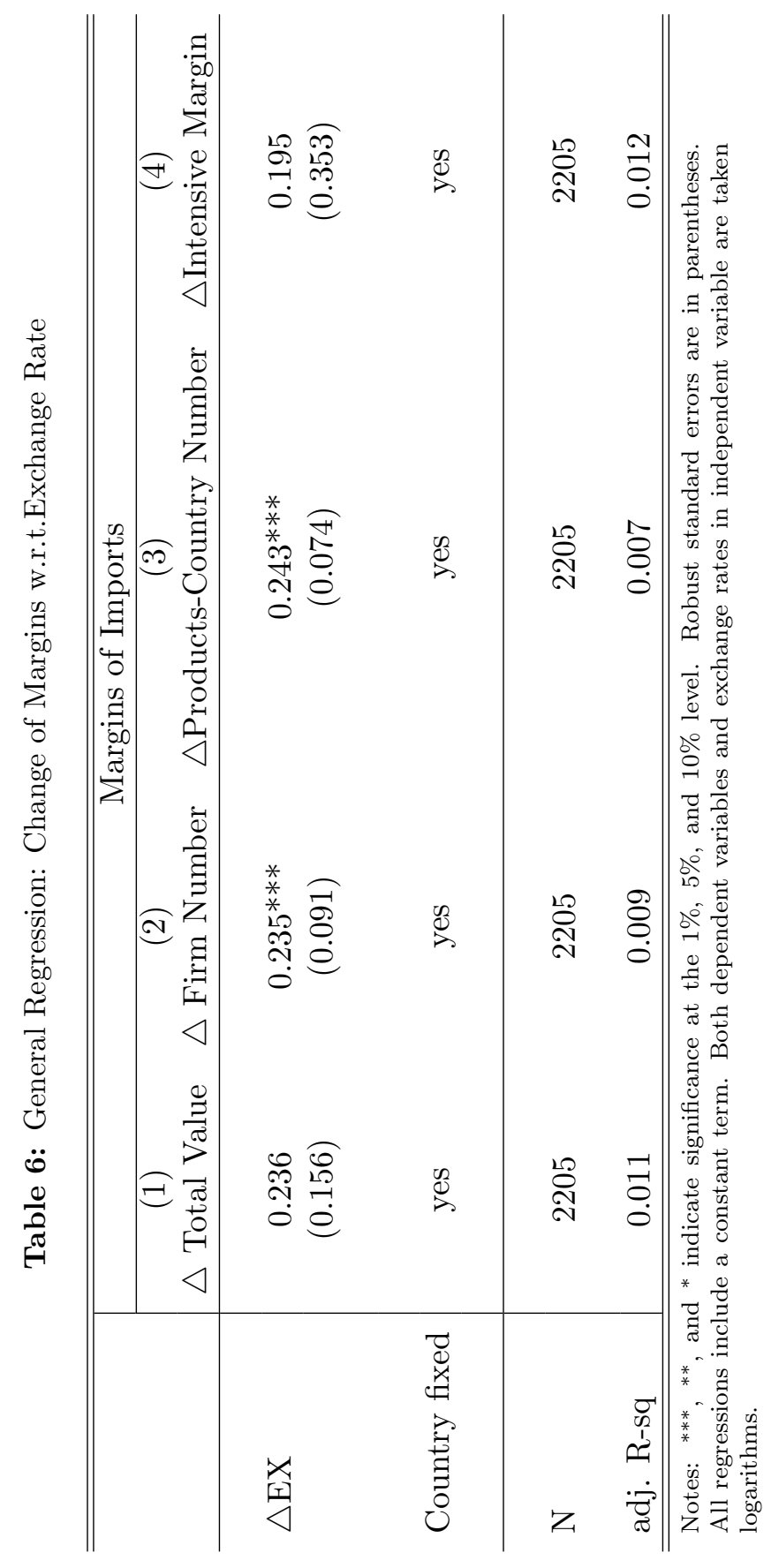




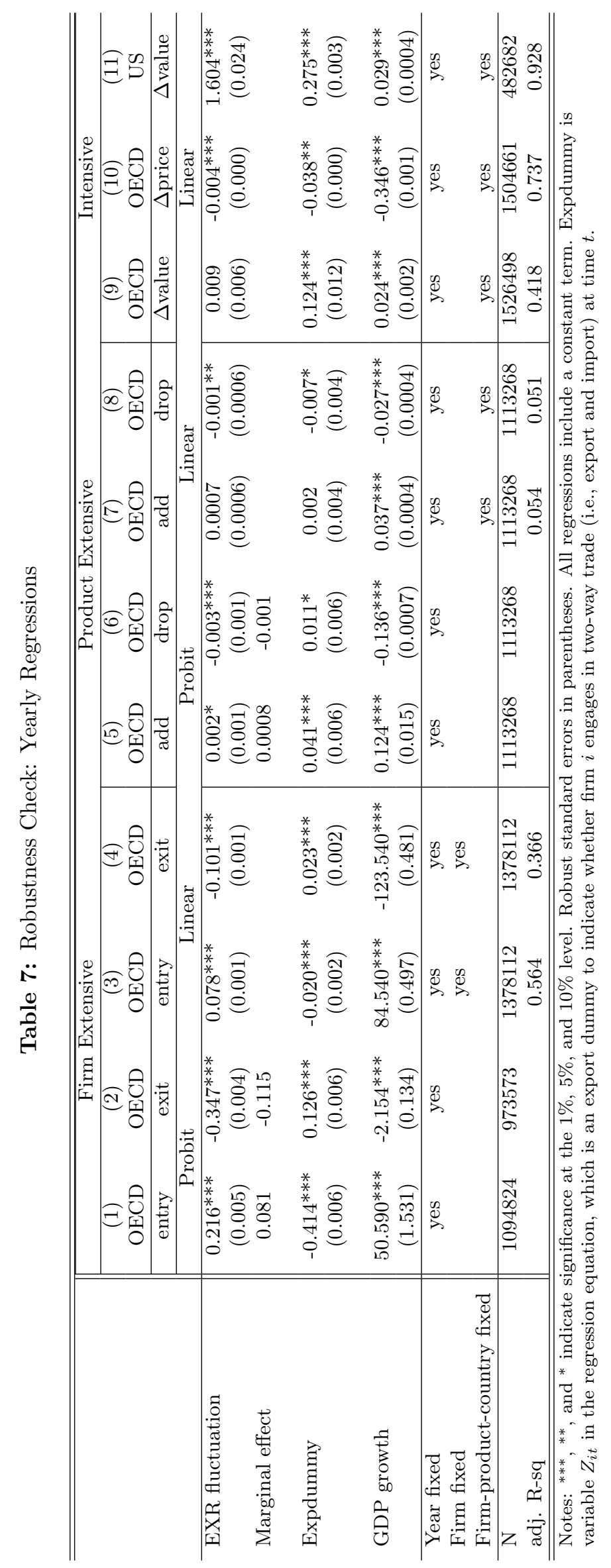




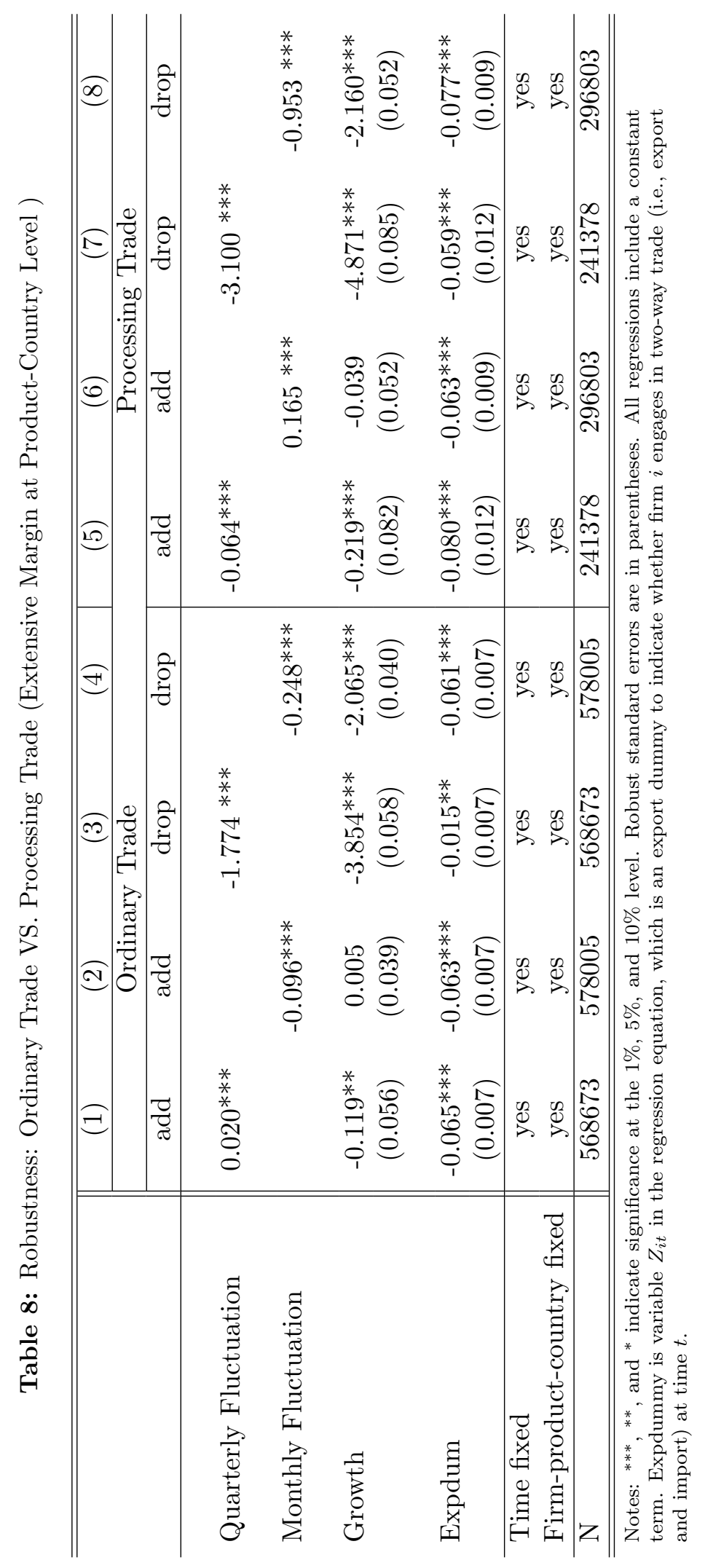




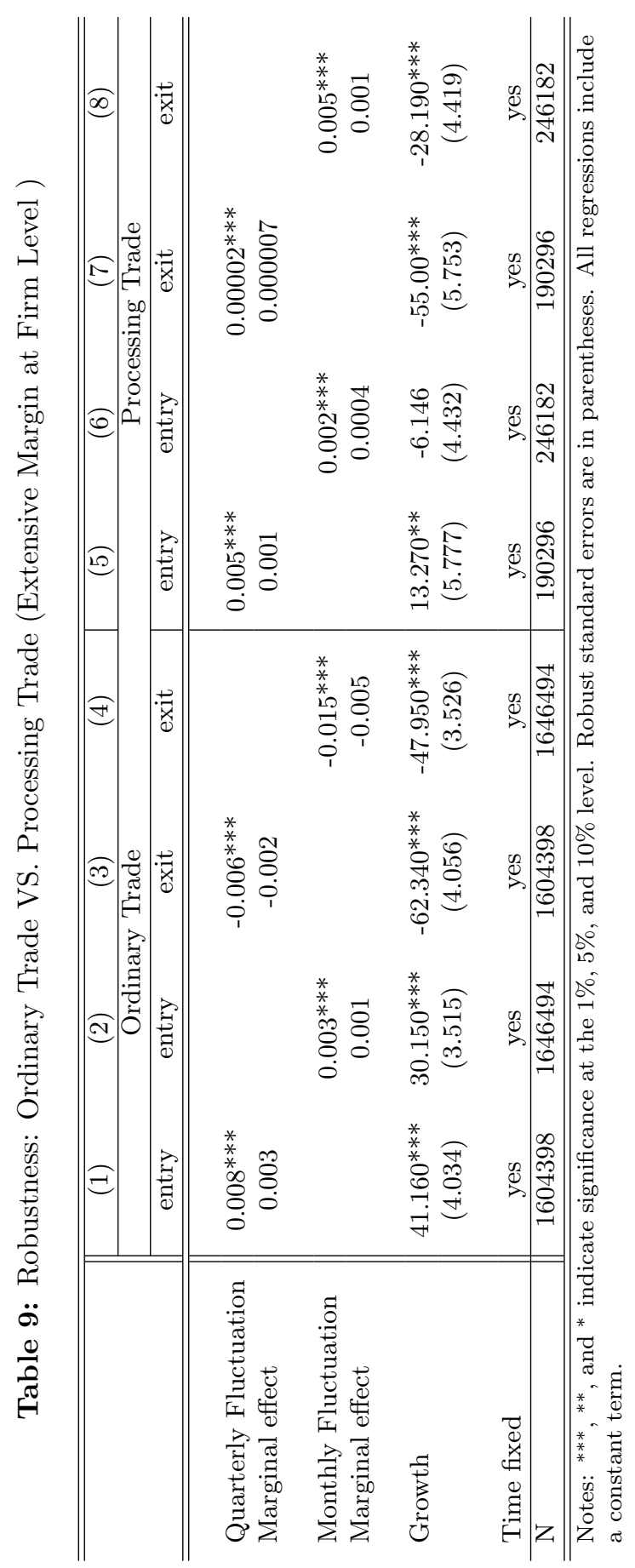




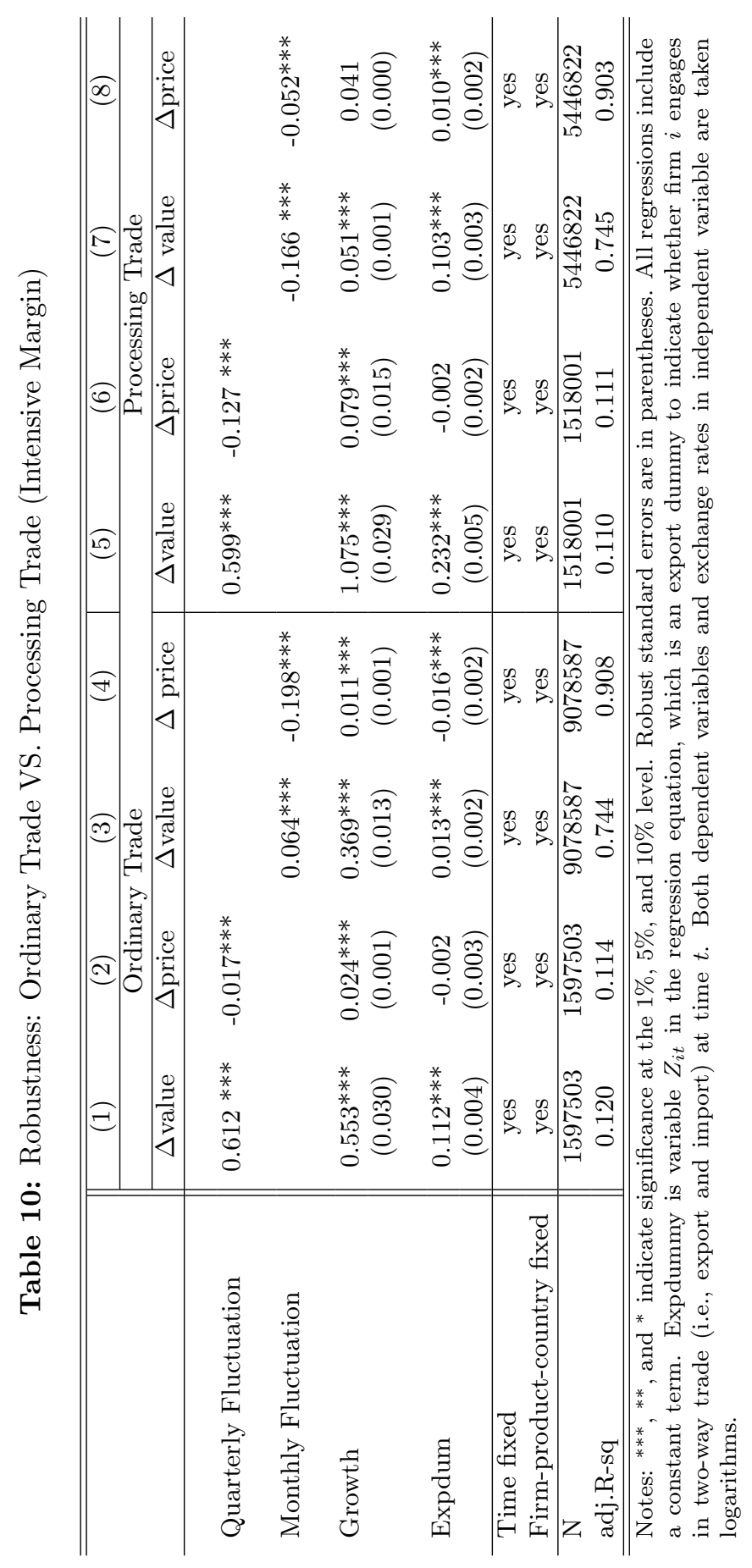




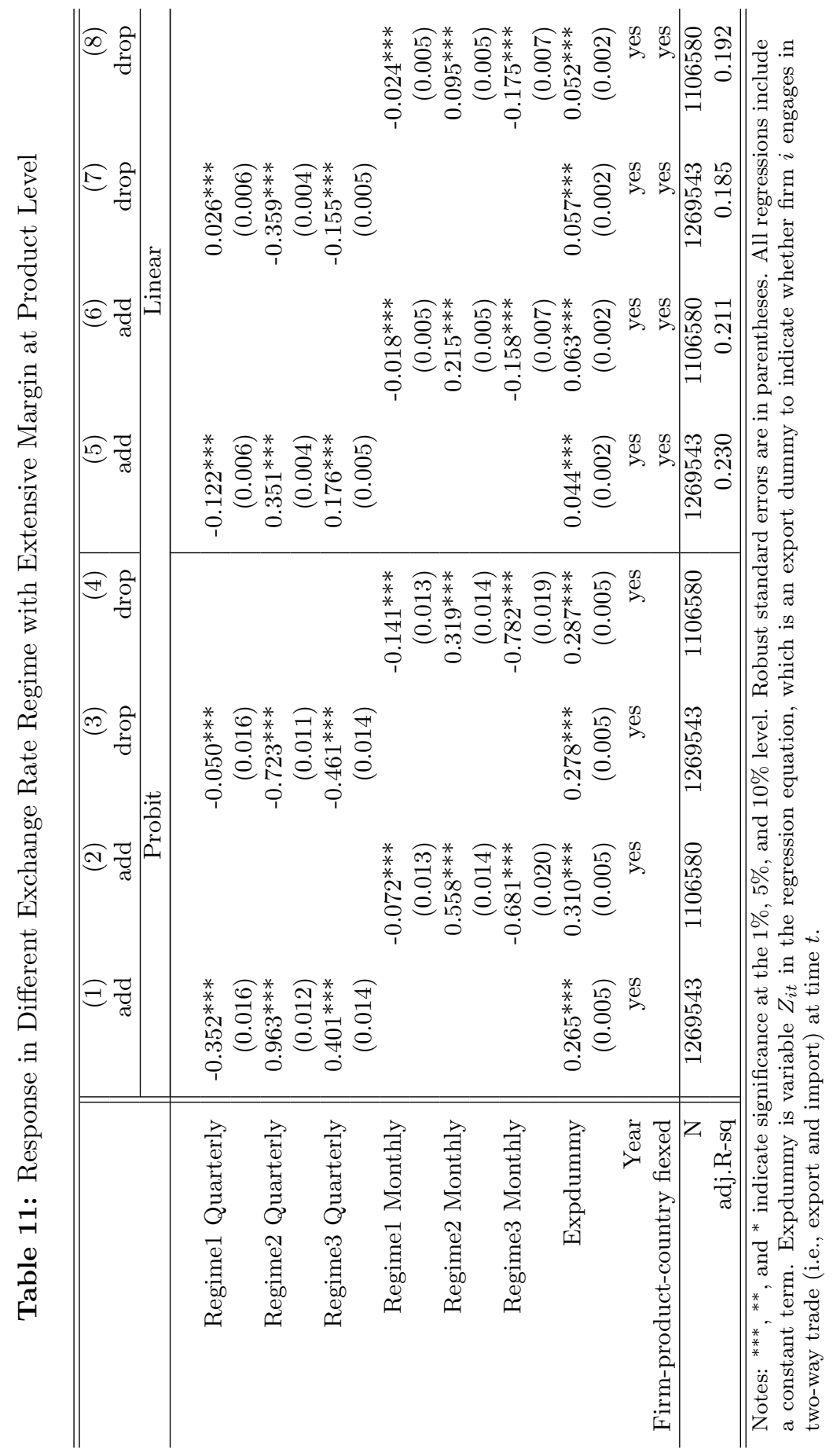




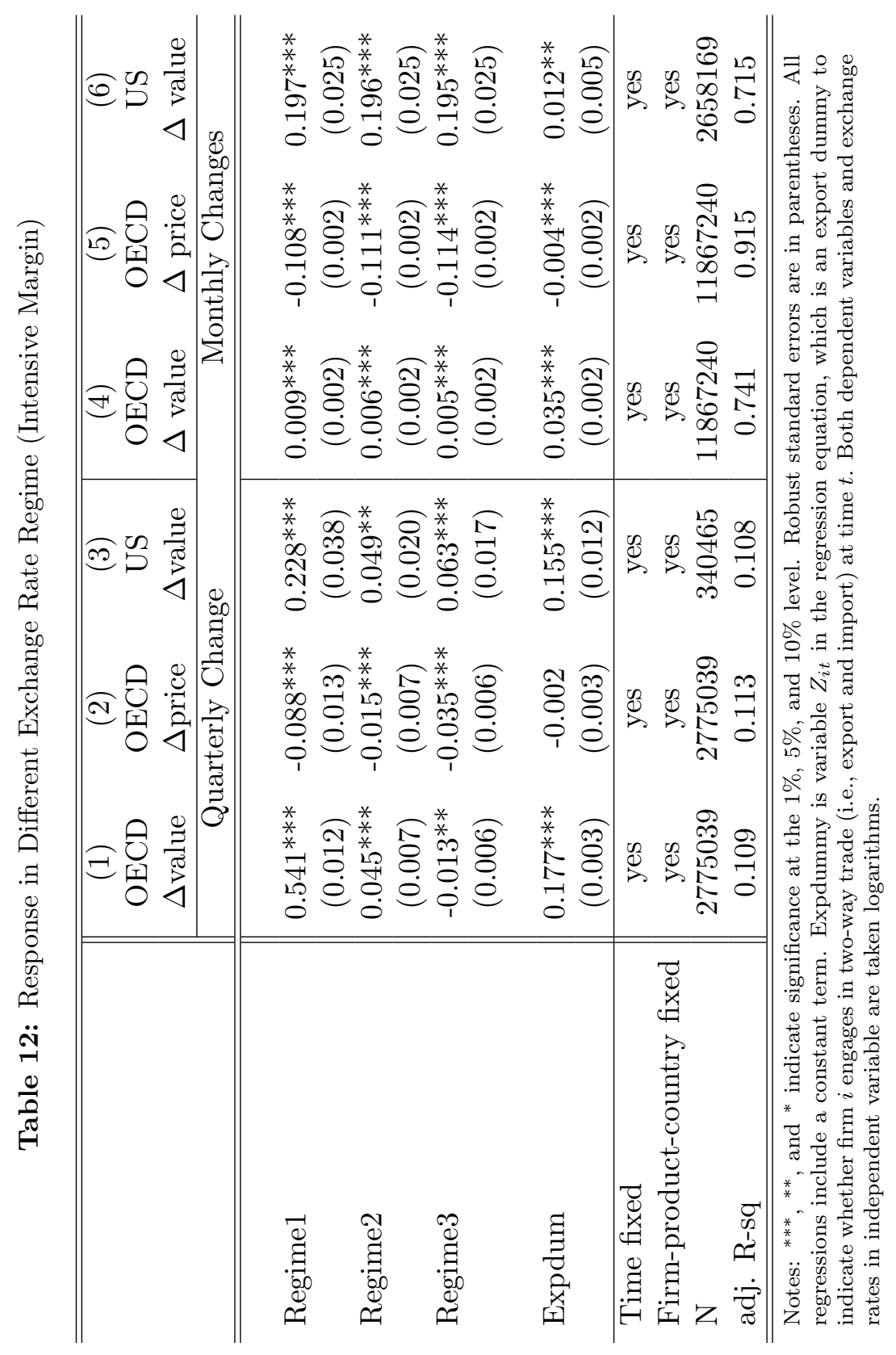




\section{Appendix}

\section{A Proof for Proposition 2}

To derive Proposition 2, we need the following condition: the slope of marginal benefit (MB) of increasing imported variety $\mathrm{N}$ is smaller than the slope of marginal cost (MC) of increasing imported variety N. This condition is illustrated in Figure A.1, and it assures that when MB curve shifts upwards during currency appreciation, the interception point $\mathrm{N}$ of MB and MC becomes larger.

To show this condition, we derive the marginal benefit function $M B$, which is given by the following equation $^{23}$

$$
M B(N)=\lambda(1-\eta) \mu A_{i}^{\eta-1} P_{X}^{-\mu \eta+\mu-1} \frac{\partial P_{X}}{\partial P_{M}} \frac{\partial P_{M}}{\partial N}>0
$$

We first show that when domestic currency appreciates, the marginal benefit curve shifts upwards, i.e., $\frac{\partial M B(N)}{\partial e}>0$. To see this, using the assumption that $P_{X}=\left(1+P_{M}^{\frac{\rho}{\rho-1}}\right)^{\frac{\rho-1}{\rho}}$ and $P_{M}=$ $\left(\int_{j=1}^{N} p_{m j}^{\frac{\theta}{\theta-1}}\right)^{\frac{\theta-1}{\theta}}=N^{\frac{\theta-1}{\theta}} p_{m}$, we have

$$
M B(N)=\lambda(1-\eta) \mu A_{i}^{\eta-1} P_{X}^{-\mu \eta+\mu-1}\left(1+P_{M}^{\frac{\rho}{\rho-1}}\right)^{-\frac{1}{\rho}} P_{M}^{\frac{1}{\rho-1}}\left(\frac{\theta}{\theta-1}\right) N^{-\frac{1}{\theta}} p_{m}
$$

Or,

$$
M B(N)=\lambda(1-\eta) \mu A_{i}^{\eta-1}\left(\frac{\theta}{\theta-1}\right) N^{-\frac{1}{\theta}}\left(N^{\frac{\theta-1}{\theta}}\right)^{\frac{1}{\rho-1}} P_{X}^{-\mu \eta+\mu-1+\frac{1}{1-\rho}} p_{m}^{\frac{1}{\rho-1}+1}
$$

Define $\Xi=\lambda(1-\eta) \mu A_{i}^{\eta-1}\left(\frac{\theta}{\theta-1}\right) N^{-\frac{1}{\theta}}\left(N^{\frac{\theta-1}{\theta}}\right)^{\frac{1}{\rho-1}}$, then

$\frac{\partial M B(N)}{\partial e}=\Xi\left[\left(-\mu \eta+\mu-1+\frac{1}{1-\rho}\right) P_{X}^{-\mu \eta+\mu-2+\frac{1}{1-\rho}} \frac{\partial P_{X}}{\partial e} p_{m}^{\frac{1}{\rho-1}+1}+P_{X}^{-\mu \eta+\mu-1+\frac{1}{1-\rho}}\left(\frac{\rho}{\rho-1}\right) \frac{\partial p_{m}}{\partial e}\right]$

Since $\eta>1,0<\theta<1, \Xi>0$. Also, $0<\rho<1,0<\mu<1, \frac{\partial P_{X}}{\partial e}<0$ and $\frac{\partial p_{m}}{\partial e}<0$, so as long as $\left(-\mu \eta+\mu-1+\frac{1}{1-\rho}\right)<0, \frac{\partial M B(N)}{\partial e}>0$ always holds.

In other words, if $\rho$ is small enough such that

$$
\rho<\frac{\mu(\eta-1)}{1+\mu(\eta-1)}<1
$$

We will have the marginal benefit function of MB shift up when domestic currency appreciates.

Now we derive the slope of the $M B(N)$ curve. Since $\frac{\partial P_{M}}{\partial N}<0$, and $\eta>1$, the slope of MB curve

\footnotetext{
${ }^{23}$ For simplicity, we drop the subscript $i$ for $P_{X}$ and $P_{M}$ in the following equations.
} 


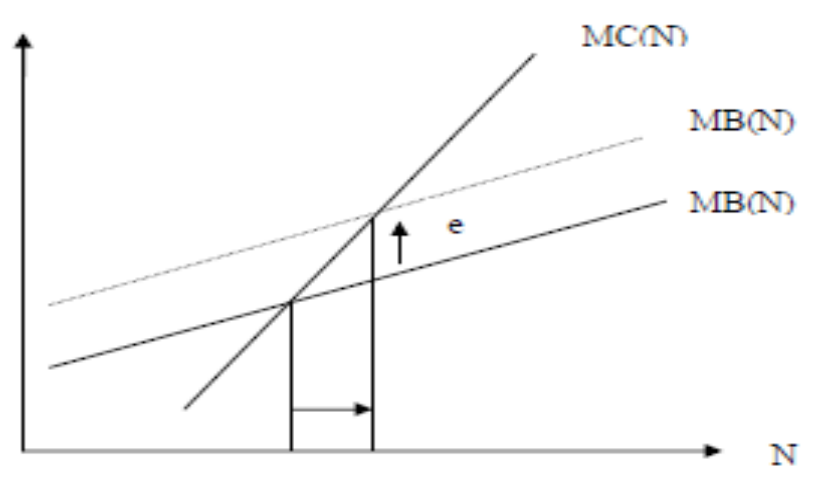

Figure A.1: Condition of Proposition 2

becomes

$$
\frac{\partial M B(N)}{\partial N}=\lambda(1-\eta) \mu A_{i}^{\eta-1} \frac{\partial P_{X}}{\partial P_{M}}\left[(-\mu \eta+\mu-1) P_{X}^{-\mu \eta+\mu-2} \frac{\partial P_{X}}{\partial P_{M}}\left(\frac{\partial P_{M}}{\partial N}\right)^{2}+P_{X}^{-\mu \eta+\mu-1} \frac{\partial^{2} P_{M}}{\partial N^{2}}\right]
$$

Also, we have

$$
\begin{gathered}
\frac{\partial P_{M}}{\partial N}=\frac{\theta-1}{\theta} N^{-\frac{1}{\theta}} P_{M} \\
\frac{\partial^{2} P_{M}}{\partial N^{2}}=\frac{\theta-1}{\theta}\left(-\frac{1}{\theta}\right) N^{-\frac{1}{\theta}-1} P_{M}
\end{gathered}
$$

By inserting $\frac{\partial P_{M}}{\partial N}$ and $\frac{\partial^{2} P_{M}}{\partial N^{2}}$ into $\frac{\partial M B(N)}{\partial N}$ equation, we have the following

$$
\begin{aligned}
\frac{\partial M B(N)}{\partial N} & =\lambda(1-\eta) \mu A_{i}^{\eta-1} \frac{\partial P_{X}}{\partial P_{M}} \\
& *\left[\frac{\partial P_{X}}{\partial P_{M}}(-\mu \eta+\mu-1) P_{X}^{-\mu \eta+\mu-2}\left(\frac{\theta-1}{\theta}\right)^{2} N^{-\frac{2}{\theta}} P_{M}^{2}+P_{X}^{-\mu \eta+\mu-1} \frac{\theta-1}{\theta}\left(-\frac{1}{\theta}\right) N^{-\frac{1}{\theta}-1} P_{M}\right]
\end{aligned}
$$

On the other hand, we assume that fixed cost for importing $f_{i m p}(N)$ is a convex function of variety $N$. For example, a specific form of $f_{i m p}(N)$ function could be

$$
f_{i m p}(N)=f N^{\gamma}, \text { where } \gamma>1
$$

So the marginal cost of importing an extra variety $M C(N)$ and the slope of the $\mathrm{MC}(\mathrm{N})$ curve with respect to $\mathrm{N}$ become

$$
M C(N)=\frac{\partial f_{i m p}(N)}{\partial N}>0, \text { and } \frac{\partial M C(N)}{\partial N}=\frac{\partial f_{i m p}^{2}(N)}{\partial N^{2}}=f \gamma(\gamma-1) N^{\gamma-2}
$$


We can see that $M C(N)$ is independent of $e$. So a sufficient condition for Proposition 2 is that $\frac{\partial M B(N)}{\partial N}<\frac{\partial M C(N)}{\partial N}$. In other words, the slope of MC curve should be larger than MB curve. Then with a domestic currency appreciation, the MB curve shifts upwards and $\mathrm{MC}$ curve remains unchanged. The interception point will rise, as illustrated in Figure A.1. Substituting terms into the above inequality condition yields

$$
\lambda(1-\eta) \mu A_{i}^{1-\eta} \frac{\partial P_{X}}{\partial P_{M}} P_{X}^{-\mu \eta+\mu-1} \frac{\partial P_{M}}{\partial N}\left[\frac{\partial P_{X}}{\partial P_{M}}(-\mu \eta+\mu-1) P_{X}^{-1}\left(\frac{\partial P_{M}}{\partial N}\right)-\frac{1}{\theta} \frac{1}{N}\right]<\frac{\partial f_{i m p}^{2}(N)}{\partial N^{2}}
$$

With simple simulation, the above condition could be satisfied if the parameter $\gamma$ is a large constant. Intuitively, because $\eta>1,-\mu \eta+\mu-1<0$, and $\frac{\partial P_{M}}{\partial N}<0$, the LHS is an increasing function of N. On the other side, since $\gamma>1$, the $\frac{\partial f_{i m p}^{2}(N)}{\partial N^{2}}$ in RHS is also positive and increasing in N (e.g., $\left.f_{i m p}(N)=f N^{\gamma}\right)$. Since the slope of the $M C(N)$ curve with respect to $\mathrm{N}$ is determined by the parameter $\gamma$, as long as $\gamma$ is large enough, the slope of the $M C(N)$ curve is higher than that of the $M B(N)$ curve and the condition in Figure A.1 is satisfied.

\section{B Import Frequency Analysis}

In this appendix, we look at frequency of import adjustment, such as how long (in terms of the number of months) a firm continually imports from abroad, imports the same product from abroad, and how many times it changes its major imported product. If most firms are continuing importers, we are more confident when we use monthly data to analyze the short-run import response to exchange rate movement.

Table B.1 presents the summary statistics of import frequency. Columns 1 and 2 show that within one year how many months firms import continually. We list percentage of firms by the duration in their continuous importing. We find that more than $71 \%$ of firms import in all twelve months within a year. In other words, seasonal importing firms who only import for a few months in a specific season only constitute a small percentage among all importers.

[INSERT TABLE B.1]

In columns 3 and 4 of Table B.1, we report how many months firms consistently import the same HS4 product within one year. The results show that firms also tend to import the same HS4 product frequently. This will also alleviate the concern for the short-run analysis of product-level extensive margin. The mean interval of importing the same product is over 8.86 months, suggesting that most Chinese importers are importing the same HS4 product for at least three out four quarters within one year. We also investigate how many times importers change their major product in columns 5 and 6, where major product is defined as the HS4 product with the largest import value within a given month. The results show that about 21 percent of firms do not change their major product within 
one year, and the majority of importing firms switch major product less than three times in one year.

Table B.1: Summary Statistics of Frequency Analysis: Firm Entry and Product Churning within One year

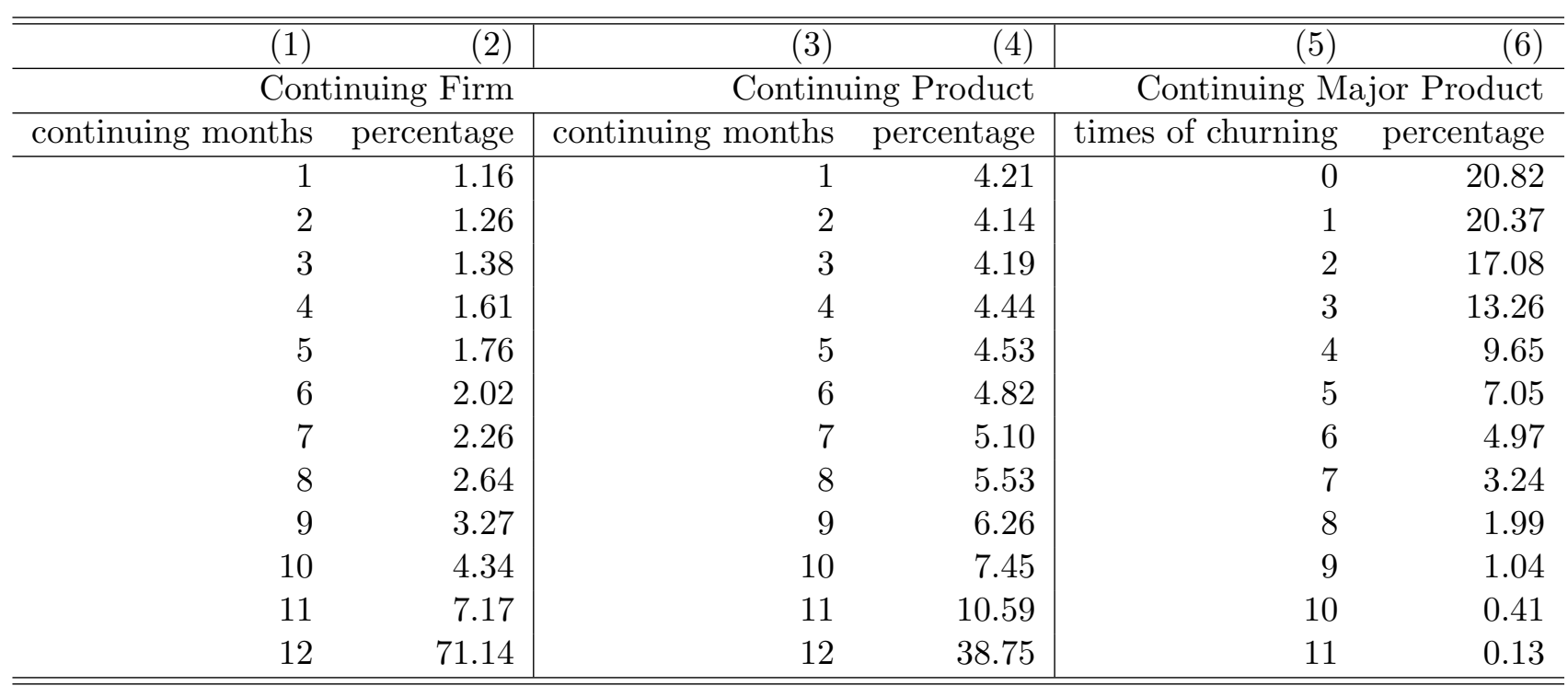

Notes: In this table we use 2005 as sample year. We also experimented with other years and obtained similar results. 